
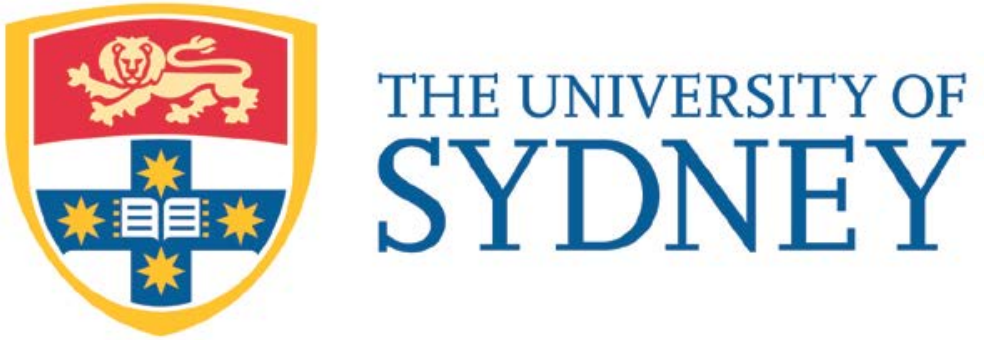

Economics Working Paper Series

$2000-01$

\title{
When the Bubble Bursts: \\ Monetary Policy Rules and Foreign Exchange Market Behavior
}

Nicoletta Batini* and Edward Nelson** University of Sydney

October 2000

(Introductory Note added January 2017) 


\title{
When the Bubble Bursts: Monetary Policy Rules and Foreign Exchange Market Behavior
}

\author{
Nicoletta Batini* and Edward Nelson** \\ October 2000 \\ (Introductory Note added January 2017)
}

\begin{abstract}
We examine the effects of a "bubble" in the foreign exchange market, defined as an exogenous process that temporarily shifts the exchange rate away from the value implied by fundamentals. The bubble process is analogous to Bernanke and Gertler's (1999) specification of an asset price bubble. We evaluate the performance of alternative simple monetary policy rules under both bubble and no-bubble scenarios and investigate whether policymakers should react to the deviation of the exchange rate from its steady-state value.
\end{abstract}

The policy experiments employ a small-scale forward-looking structural model calibrated to UK data, which we previously used in Batini and Nelson (2000). For this model, which includes an uncovered interest parity condition, we find that the appropriate response to the exchange rate is captured by the expected inflation term, provided that the response coefficient and the inflation horizon are optimized. When uncovered interest parity is relaxed, there appears to be more merit in incorporating a separate exchange rate term in the monetary policy rule.

* MPC Unit, Bank of England, Threadneedle Street, London EC2R 8AH, United Kingdom. Tel: +44 207601 4354. Fax: +44 2076013550.

E-mail: nicoletta.batini@bankofengland.co.uk

** Affiliate, Centre for Economic Policy Research. Address correspondence to: Edward Nelson, Bank of England, Threadneedle Street, London EC2R 8AH, United Kingdom. Tel: +44207601 5692. Fax: +442076013550.

E-mail: ed.nelson@bankofengland.co.uk

We thank Larry Ball, Mark Gertler, and Charles Goodhart for valuable discussions. All errors are our own. The views expressed herein are those of the authors and should not be interpreted as those of the Bank of England or the Monetary Policy Committee. 
Introductory Note (January 2017)

This paper, which was prepared for a conference in October 2000, did not receive the postconference revision and finalization that the authors for a long time intended to give it.

The paper has sporadically been available on the web since its initial appearance and is being added to this working paper series to make it more easily accessible.

Edward Nelson

Email: Edward.Nelson@sydney.edu.au 


\section{Introduction}

The nominal exchange rates of many countries fluctuate considerably on a daily basis. A substantial fraction of this variability persists even when exchange rate data are timeaggregated to a quarterly frequency. And, as many observers have noted, much of the observed variation in quarterly nominal exchange rates is also apparent in real exchange rates (e.g. Mussa, 1986; Monacelli, 1999a).

Real exchange rates are one of the key asset prices in the economy. A number of economists have expressed concern that, while some fluctuations in the real exchange rate and other asset prices reflect responses to fundamental economic shocks, a substantial proportion may be due to "nonfundamental" forces that push asset prices in a particular direction for a prolonged period of time, creating an asset price "bubble" (see, among others, Grossman and Shiller, 1981; Okina, 1984; Evans, 1986; Borensztein, 1987; Wu, 1995; and Charemza, 1996). Recently, there has been much debate about whether policymakers should attempt to restrain or "prick" perceived asset price bubbles. In particular, a key question is whether monetary policy makers should respond explicitly to deviations of asset prices from their steady-state or fundamental levels as part of their pursuit of inflation and output gap stability (see e.g. Kent and Lowe, 1997; Cogley, 1999; Bernanke and Gertler, 1999; Allen and Gale, 2000, and Cecchetti, Genberg, Lipski, and Wadhwani, 2000).

Much of this discussion has been motivated by the behavior of the US stock market during the mid- and late 1990s. However, the behavior of exchange rates in certain periods has seemed suggestive of "exchange rate bubbles." For example, some commentators have claimed that the appreciation of the US dollar from 1980 to 1985 was excessive relative to underlying fundamentals (e.g. Okina, 1984, and Evans, 1986). Similarly, it is difficult to reconcile the appreciation of the UK exchange rate in the late 1990s (see Table 1) with uncovered interest parity or with standard models of the equilibrium real exchange rate. The labeling of the level of the UK exchange rate as "unsustainable" in the Bank of England's February 2000 Inflation Report is informative in this respect. 


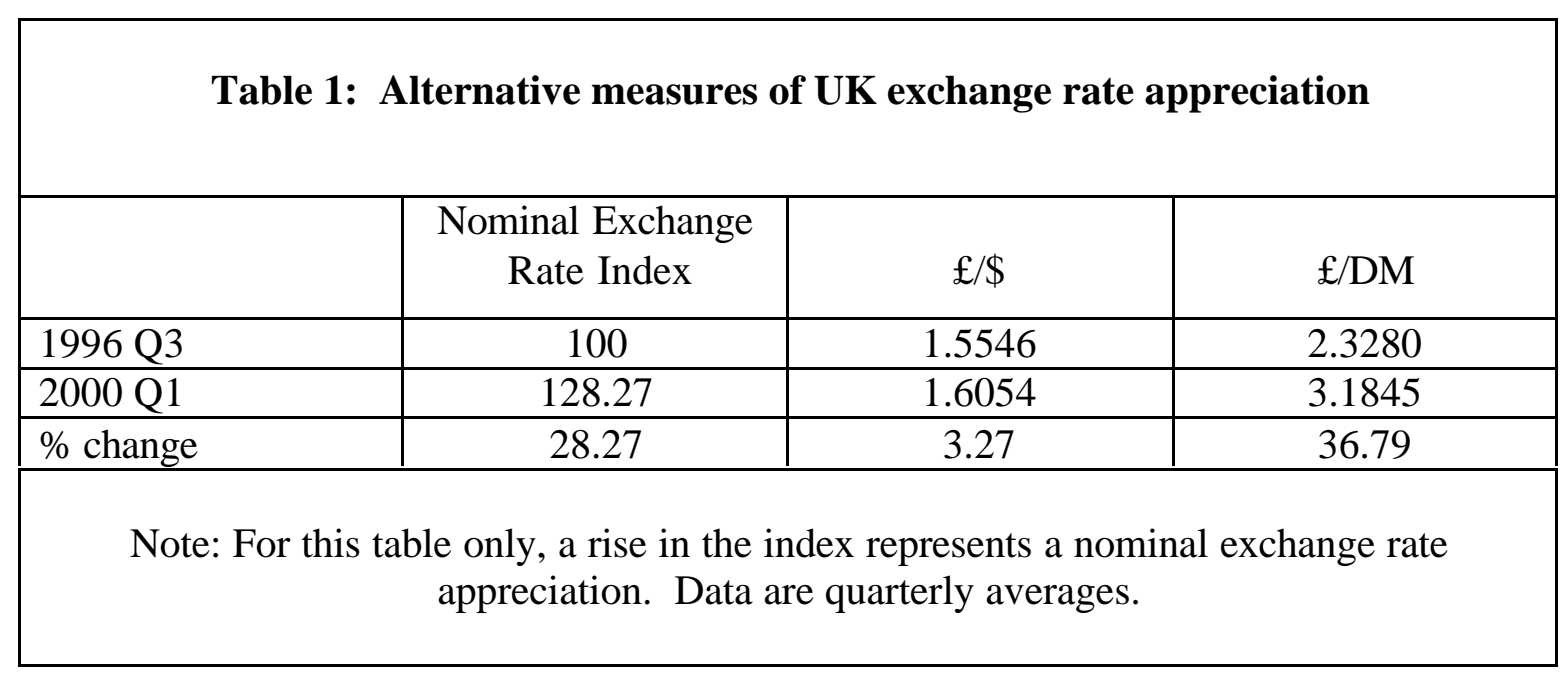

To the extent that asset prices matter for spending and pricing decisions in goods markets, they are a relevant variable for forecasting inflation. The question is whether this implies that inflation-targeting central banks should respond to asset prices specifically.

Several observers, including recently Bernanke and Gertler (1999) and Vickers (1999), have argued that the appropriate response by policy makers to asset prices is fully captured by responding to expected inflation. On the other hand, Cecchetti, Genberg, Lipski, and Wadhwani (CGLW) (2000) maintain that there is a gain in macroeconomic performance from incorporating a separate response to asset prices in a monetary policy rule, over and above the expected inflation term. All the studies mentioned here agree that it is appropriate to respond to asset prices in some way; the area of contention is: does expected inflation serve as a sufficient statistic for the effects of asset prices on welfare, so that, given expected inflation, there is no role for asset prices in monetary authorities' reaction functions?

In this paper, we examine whether it is desirable to respond to asset prices when the economy is described by a forward-looking, open-economy macroeconomic model that we have used in previous work (Batini and Nelson, 2000). CGLW (2000) report some results using a version of this model and find that, when exchange rate shocks alone are 
operative, there may be welfare gains from responding to the exchange rate. But, because their findings are based on experiments that abstract from which IS and Phillips curve shocks, CGLW leave open the question of whether a separate response to exchange rates is justified when all shocks are present—a question which we address in this paper.

In addition, we report the results of responding to the exchange rate in a policy rule both with and without the presence of "bubbles"-while CGLW only consider no-bubble scenarios when they consider policy responses to the exchange rate. The particular bubble process we use is similar to that used in Bernanke and Gertler (1999). As in their experiments, a bubble is defined as an exogenous process that, for a time, drives an asset price in an explosive fashion away from its fundamental level. In the Bernanke-Gertler exercises, the asset price subject to a bubble is a stock price. We focus, instead, on a bubble in the foreign exchange market. We believe this is of interest for several reasons. First, as noted above, exchange rates have been suspected of occasionally being driven by nonfundamental factors. Secondly, the exchange rate is a key variable for output and inflation behavior in virtually every open-economy macroeconomic model, in contrast to stock prices, which do not matter for aggregate demand (for a given real interest rate) in many models. Finally, unlike many other asset prices, exchange rates potentially have effects on the price level over and above their effect on aggregate demand, due to the presence of import prices in consumer price indices.

The paper is organized as follows. Section 2 describes our model and describes in detail the interaction in the model between asset prices and macroeconomic behavior. Section 3 describes our loss function and how we specify the "bubble" in our simulation experiments. Section 4 presents results obtained from stochastic simulations of the model under alternative monetary policy rules-both with and without explicit responses to the real exchange rate. We investigate the extent to which the presence of a bubble changes the appropriate horizon for inflation targeting, and the appropriate response of monetary policy to exchange rates. In Section 5, we contemplate two extensionsallowing agents to view the bubble probabilistically; and dropping uncovered interest parity. Section 6 concludes. 


\section{The model}

\subsection{Model specification}

The model we use in this paper is the same as that used in our earlier study of optimal horizons for inflation targeting (Batini and Nelson, 2000). The structural equations of the model are:

$y_{t}=\mathrm{E}_{t} y_{t+1}-\sigma\left(R_{t}-\mathrm{E} \pi_{t+1}\right)+\delta \tilde{q}_{t-1}+v_{t}$

$\pi_{t}=\alpha \pi_{t-1}+(1-\alpha) \mathrm{E}_{t} \pi_{t+1}+\varphi_{y} y_{t-1}+\varphi_{q} \Delta \tilde{q}_{t-1}+u_{t}$

$\mathrm{E}_{t} q_{t+1}=q_{t}+R_{t}-\mathrm{E}_{t} \pi_{t+1}+\kappa_{t}+z_{t}$

where $y_{t}$ is $\log$ output, $R_{t}$ is the nominal interest rate (in quarterly fractional units), $\pi_{t}$ is quarterly inflation, $q_{t}$ is the log real exchange rate (measured so that a rise is a

depreciation), and $\tilde{q}_{t}=1 / 4 \sum_{j=0}{ }^{3} q_{t-j}$ is a four-quarter moving average of $q_{t}$. These variables are all expressed relative to steady-state values. In particular, $q_{t}$ is expressed in terms of deviations from its steady-state equilibrium log value, $q^{s s}$.

Equation (1) is the IS equation. In the absence of the exchange rate terms, the IS curve would be the standard, optimization-based expectational IS function. ${ }^{1}$ The exchange rate terms are included to capture the effect of exchange rate movements on net exports and, hence, aggregate demand. Note, however, that if equation (1) had been obtained by substituting a static export demand function and the economy's resource constraint into a consumer Euler equation, then terms in current and expected future $q_{t}$ would appear rather than lagged $q_{t}$. The motivation for using lags of $q_{t}$ is largely empirical and is closely related to our treatment of the exchange rate terms in the Phillips curve, discussed below. 
The price-setting specification in equation (2) can be considered a quarterly approximation of Ball's (1999) open-economy Phillips curve. As in Ball's specification, expected inflation affects current inflation with a unit coefficient. But unlike Ball, who abstracted from any forward-looking behavior in price setting, we make inflation depend on a linear combination of its lagged value and its next-period rational expectation. This specification has been used by many authors including Fuhrer and Moore (1995), Fuhrer (1997), Roberts (1997), Bernanke and Gertler (1999), and Rudebusch (2000), and is consistent with forward-looking price setting,but with a fraction of price setters using backward-looking rules of thumb in their decision making. The specific weights we choose -0.80 on $\pi_{t-1}, 0.20$ on $\mathrm{E}_{t} \pi_{t+1}$-are Fuhrer's estimates, obtained from quarterly US data.

In equation (2), two forcing processes drive inflation. The first is $y_{t-1}$. In our model, this variable is both the output gap and output, due to our assuming that potential output is constant. The other forcing process is the real exchange rate. Following Ball, we assume that it is the prior year's change in the real exchange rate that matters for aggregate inflation behavior. This delayed response might result from slow pass-through of exchange rate changes to import prices. In Section 2.2 below, we compare the dynamics of this specification with that of a more conventional-and more forward-lookingspecification of the open-economy influences on inflation.

Together, the IS equation and Phillips curve restrict the extent to which exchange rate behavior has macroeconomic consequences, in the absence of a policy response. These restrictions take two forms. First, as with the IS equation, shorter-term fluctuations in the exchange rate do not matter for aggregate demand and inflation behavior, because private agents respond only to annual averages of the exchange rate terms. Secondly, we set the coefficients in (1) and (2) to values that appear low relative to the importance that might be suggested by the openness of the UK and similar economies. These low values are motivated by prior work by ourselves and others that suggest that exchange rate effects

\footnotetext{
${ }^{1}$ See McCallum and Nelson (1999) for a derivation of this equation from optimizing behavior. For a derivation which allows for some lags in spending decisions, see Rotemberg and Woodford (1999).
} 
are generally weak in estimated output and inflation equations for the UK (e.g. Batini and Turnbull, 2000; Nelson, 2000a; and Goodhart and Hofmann, 2000). ${ }^{2}$ Specifically we set $\delta=0.05$ in equation (1) and $\varphi_{q}=0.025$ in equation (2).

Finally, $v_{t}, u_{t}$, and $\kappa_{t}$ are stationary disturbance terms. Of these, $v_{t}$, and $u_{t}$ are exogenous IS and Phillips curve shocks. ${ }^{3} \kappa_{t}$ is an exogenous shock that creates transitory deviations from strict uncovered interest parity (UIP). When we contemplate exchange rate bubbles, we will introduce another shock beside $\kappa_{t}$, labeled $z_{t}$ in equation (3), that creates more violent, "bubble-like" deviations from UIP. We discuss this process further in Section 3 below. The stationary shocks are all assumed to be AR(1) processes:

$v_{t}=\rho_{v} v_{t-1}+\varepsilon_{v t}$

$u_{t}=\rho_{u} u_{t-1}+\varepsilon_{u t}$

$\kappa_{t}=\rho_{\kappa} \kappa_{t-1}+\varepsilon_{\kappa}$,

As in our previous work, we calibrate the IS shock process according to McCallum and Nelson's (1999) estimates-we set $\rho_{v}=0.30$ and the standard deviation of $\varepsilon_{v t}$ (denoted $\left.\sigma\left(\varepsilon_{v t}\right)\right)$ in (4) to $1 \%$. For the Phillips curve shock $\varepsilon_{u t}$, we continue to assume a white noise process $\left(\rho_{u}=0\right)$ but no longer use the $\sigma\left(\varepsilon_{u t}\right)=1 \%$ value that we used in our earlier work. This value seems excessive relative to the innovations in empirical inflation equations for the UK if 1970 s data are excluded. We instead set $\sigma\left(\varepsilon_{u t}\right)=0.5 \% .^{4}$ Finally, the UIP shock term $\kappa_{t}$ is assumed to have $\operatorname{AR}(1)$ coefficient $\rho_{\kappa}=0.753$ and innovation standard

\footnotetext{
${ }^{2}$ Similar findings have been reported for other countries. For example, Beechey et al (2000) are unable to find a significant effect of the real exchange rate in their estimated IS equation for the Australian economy. See also the results for several countries in Stock and Watson (2000).

${ }^{3} v_{t}$ can be interpreted as a shock to consumers' preferences or as an exogenous government spending sequence. The $u_{t}$ process has various interpretations, including as a pricing error by firms, or (as discussed in Clarida, Gali, and Gertler, 1999 and Erceg, Henderson, and Levin, 1999), as a disturbance to the Phillips curve that arises from labor market rigidities.

${ }^{4}$ Because of the new innovation variance, the optimal response coefficients for simple interest rate rules for this model will generally be different from those we found in Batini and Nelson (2000). Accordingly, we reoptimize these coefficients in Section 4.
} 
deviation $0.92 \%$, based on our estimates of this process using quarterly UK data for 1981 Q1-1998 Q1. All shocks are assumed to be mutually uncorrelated.

\subsection{Properties of the model}

We experiment below with policy rules that respond to asset prices-specifically, the real exchange rate-and examine the consequences of such policies for aggregate economic performance. Therefore, it is especially important to establish that the specification of the open economy elements of the model — the interaction of exchange rate changes with aggregate demand and inflation-is empirically plausible. For this reason, we now compare the model's predictions for cross-correlations between the exchange rate and other variables with those of an alternative open-economy specification, and confront both alternatives with the data. We show that our baseline model gives a better match with the data.

Alternative Phillips curve: Compared to a model that would emerge from aggregating the prices of domestically produced goods with those of imported consumer goods, the pricesetting equation (2) is missing forward-looking terms in the exchange rate. In the case of instant pass-through of exchange rate changes to import price changes, terms in $\mathrm{E}_{t} \Delta q_{t+1}$ would be present; and in a model of optimal price setting in the presence of costs of adjusting import prices, lags of $q_{t}$ would enter the aggregate price equation, as they do in (2), but expected future values of $q_{t}$ would also appear (see Monacelli, 1999b). We will concentrate on the differences between our price-setting specification and that of a more standard price-setting specification with instantaneous pass-through. Specifically, we report comparisons with an alternative version of our model in which the IS and UIP equations (1) and (3), and their calibration, are as before, but in which the parameterization of the Phillips curve is changed to:

$$
\pi_{t}=\alpha \pi_{t-1}+(1-\alpha) \mathrm{E}_{t} \pi_{t+1}+\phi_{y} y_{t-1}+0.4\left(0.8 \Delta q_{t}-0.2 \mathrm{E}_{t} \Delta q_{t+1}\right)+u_{t},
$$


which is similar to Batini and Haldane's (1999) Phillips curve, in the sense that it can arise from substituting a price-setting equation for domestically produced goods into a consumer price index, and assuming that nominal import prices move mechanically with contemporaneous nominal exchange rate movements.

Apart from the dating of the exchange rate terms, another difference of (7) from (2) is the magnitude of the coefficients on the real exchange rate-much larger in (7) than in our Phillips curve. On this score, (7) might appear more plausible a priori as its size is partly motivated by the percentage of goods in UK consumer price indices that are imported (Batini and Haldane, 1999, p. 167). But there are several reasons for believing that the appropriate values of the coefficients on real exchange rate change in the Phillips curve may nevertheless be small even in quite open economies. One reason, noted in Section 2.1 above, is the empirical difficulty to pick up sizable effects. Another is that domestic economic conditions may dominate the price-setting considerations of sellers of imported goods, in part because of "pricing to market" reasons which lead them to mimic the behavior of price setters of domestically produced goods (e.g. Bergin and Feenstra, 1999). Finally, even if import prices follow exchange rate movements closely, higher import prices may tend to leave purchasers with less to spend on non-imported goods, putting downward pressure on those goods' prices and reducing the net impact of exchange rate changes on the aggregate price level.

Matching the data: To investigate the relative empirical merits of equations (2) and (7), we now compare each specification to data, when each is supplemented by equation (1) to describe aggregate demand and equation (3) to enforce uncovered interest parity. Specifically, we will be comparing the vector autocorrelation functions generated by each model, and comparing them to those generated by UK quarterly data for 1980 Q1-1999 Q2. A policy rule is needed to generate the theoretical models' implied moments, and a rule based on empirical evidence is needed for this comparison. Due to the presence of multiple policy regime changes in the UK during the 1980-1999 sample, we have to settle on using a policy rule that describes only a portion of the sample period. The 
policy rule specification that we use is that estimated in Nelson (2000b) for the UK for 1992 Q4-1997 Q1:

$4 * R_{t}=0.29\left(4 * R_{t-1}\right)+0.90 \mathrm{E}_{t} \Delta_{4} p_{t+1}+0.32 y_{t}+4 * e_{R t}$.

A shock standard deviation of $0.1 \%$ (or $0.4 \%$ in annualized units) is used. ${ }^{5}$

The vector autocorrelation function for the variables $\left[y_{t} \Delta p_{t} R_{t} q_{t} \Delta q_{t}\right]^{\prime}$ for our baseline specification (solid lines) and UK data (broken lines) are given in Figure 1. The data correlations are computed from UK data on linearly detrended log output (our $y_{t}$ measure), the quarterly seasonally adjusted log-change in the RPIX price index $\left(\Delta p_{t}\right)$, the nominal Treasury bill rate $\left(R_{t}\right)$, and the real exchange rate $\left(q_{t}\right.$, the log of the inverse of the IMF's real exchange rate measure $),{ }^{6}$ and its quarterly first difference $\left(\Delta q_{t}\right)$.

In both the data and our model, the correlations between $\Delta p_{t}$ and $q_{t-j}$ and $\Delta q_{t-j}$ are negative for $j \geq 0$. If we move away from the price-setting equation in our model in favor of equation (7), the correlations between $\Delta p_{t}$ and current and lagged $q$ and $\Delta q$ become positive. Thus, the Phillips curve (7) produces counterfactual predictions about the dynamic relationship between asset price movements and movements in current and future inflation, but our baseline model (with equation (2)) does not. Given the importance of this relationship for the issues that we are concerned with in this paper, use of our baseline model seems preferable, despite the less firm theoretical foundations for the manner in which the $q_{t}$ terms enter the Phillips curve.

\footnotetext{
${ }^{5}$ This is in the range of values found for estimated monetary policy reaction functions for the US and the UK over 1980-1999. It is larger than the policy shock standard deviation found by Nelson for the UK for 1992-1997, but the low value he found may largely reflect the brevity of the estimation period.

${ }^{6}$ The inversion is necessary to make rises in $q_{t}$ correspond to depreciations, as they do in our theoretical model.
} 

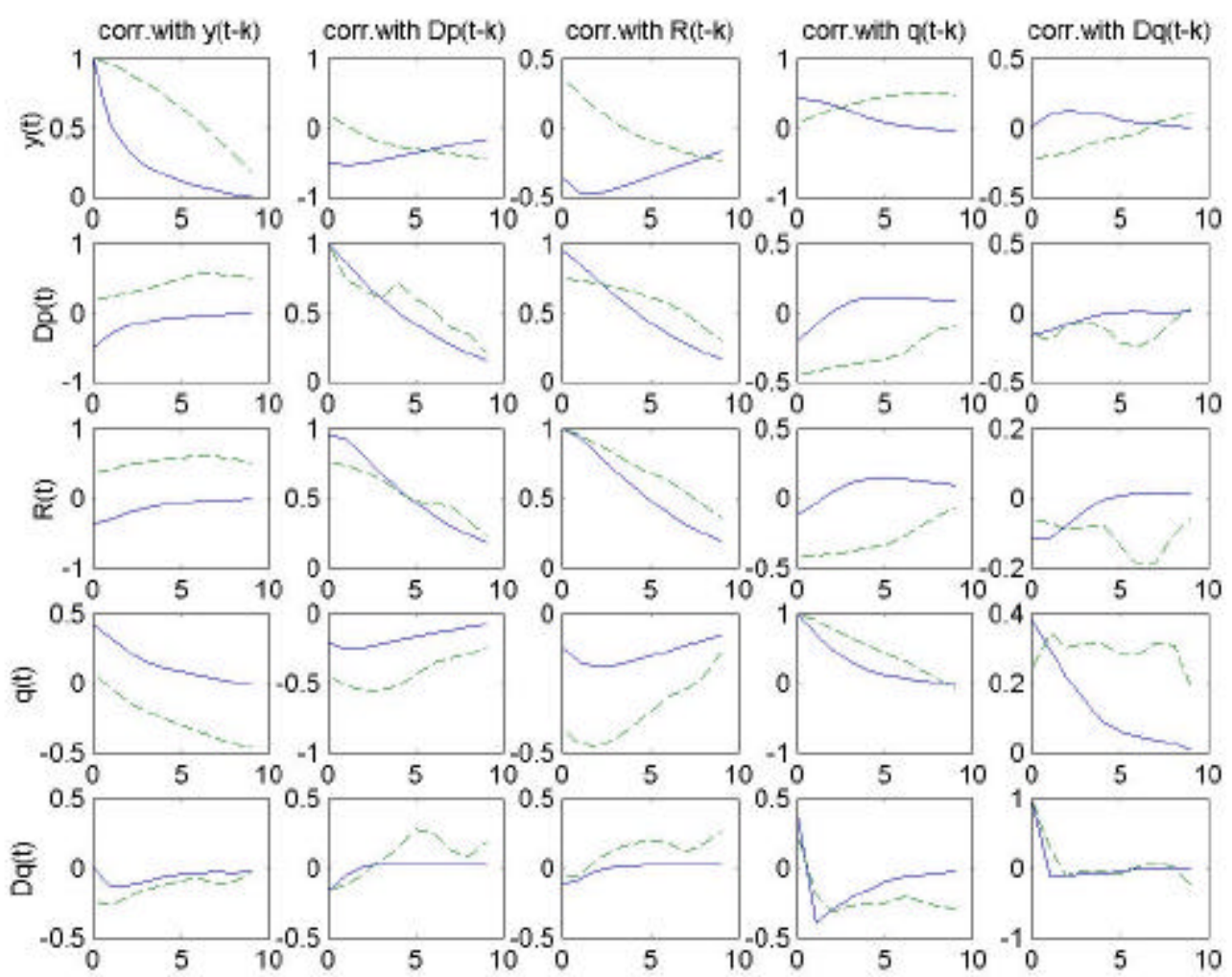

Figure 1: Vector Autocorrelations: Data and Model 


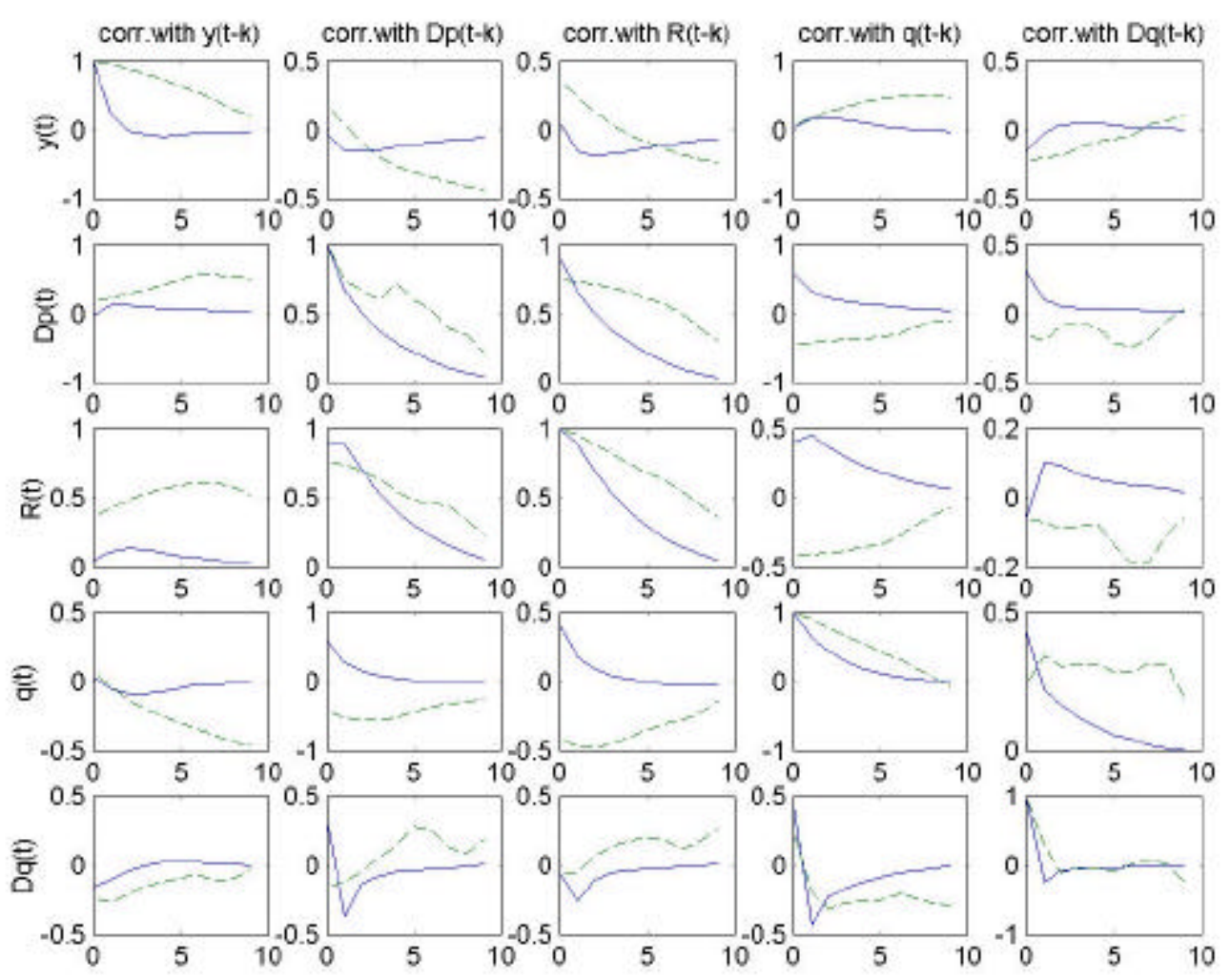

Figure 2: Vector Autocorrelations: Data and Model with BH Price Specification 


\section{Loss function and specification of the bubble}

In our quantitative work below, we will evaluate the welfare performance of various parameter settings for the nominal interest rate feedback rule:

$R_{t}=\phi_{\pi} \mathrm{E}_{t} \pi_{t+k}+\rho_{R} R_{t-1}+\phi_{q} q_{t-1}$,

where $\phi_{\pi}>0, \rho_{R} \in[0,1]$, and $\phi_{q} \geq 0$. This rule is one in which policy responds to inflation expected $k$ periods ahead, and to lagged real asset prices, as in Bernanke and Gertler (1999). As noted earlier, in our case the asset price is the log real exchange rate, $q_{t}$. In keeping with much other work on policy rules, we also allow for, but do not impose, a degree of interest rate smoothing (i.e., dependence of $R_{t}$ on its lagged value). In line with our previous work, in contemplating alternative rules, we consider not only different values for the coefficients $\left(\phi_{\pi}, \rho_{R}, \phi_{q}\right)$ but also different feedback horizons (the value of $k$ in rule (9)) - alternative dates in the future for the inflation forecast used in the monetary policy rule. Much of our interest is in the merits of nonzero $\phi_{q}$ values, and the effect that the presence of exchange rate "bubbles" (defined below) has on the choice of both the optimal exchange rate response $\phi_{q}$, and on the optimal feedback horizon $k$.

The objective function that we use to rank alternative rules is:

$L=\lambda \pi \operatorname{Var}\left(4 * \pi_{t+j}\right)+\lambda y \operatorname{Var}\left(y_{t}\right)+\lambda_{\Delta R} \operatorname{Var}\left(4 * \Delta R_{t}\right)$

where $4 * \pi_{t}$ is annualized quarterly inflation, $y_{t}$ is the log output gap, and $\lambda \pi, \lambda y$, and $\lambda_{\Delta R}$ denote the weights assigned to inflation deviations from target, output deviations from potential, and volatility in the first difference of the nominal interest rate, respectively. ${ }^{7}$ $\operatorname{Var}(\bullet)$ denotes unconditional variance of a variable. Equation (10) is the objective

\footnotetext{
${ }^{7}$ Inflation-targeting central banks are often judged by their ability to keep inflation close to target in the manner most consistent with minimizing departures of output from potential. Both these concerns are captured in (10). Two differences of (10) from the criteria on which central banks are judged are that inflation is an annualized quarterly rate in (10), not a four-quarter rate; and there is a penalty for interest rate variations. In Section 4 below we discuss the effect of the latter term on our results.
} 
function used in Rudebusch and Svensson (1999). As they note, it can be regarded as the unconditional mean of the intertemporal loss function of the form $\mathrm{E}_{t} \Sigma_{j=0}{ }^{\infty} \beta^{j}\left[\lambda \pi\left(4 * \pi_{t+j}\right.\right.$ $\left.\left.-4^{*} \pi_{t+j}{ }^{T}\right)^{2}+\lambda y\left(y_{t+j}-y_{t+j}{ }^{T}\right)^{2}+\lambda_{\Delta R}\left(4^{*} \Delta R_{t+j}\right)^{2}\right]$, where the inflation target $\pi_{t}^{T}$ is constant, the output target $y_{t}^{T}$ is equal to potential output (which is constant in our experiments), and the discount factor $\beta$ approaches unity. We use the weights $\lambda \pi=1.0, \lambda y=1.0$, and $\lambda_{\Delta R}=0.5$, following Rudebusch and Svensson's baseline values. However, because there is considerable debate over the appropriate weights suggested by theory (see Woodford, 1999), we also report the values of the individual components of the loss function. ${ }^{8}$

In Section 4 below, we report the outcomes of two sets of experiments. In the first set, there is no bubble in any period. In this case, the variable $z_{t}$ does not appear in the UIP condition (3), whose only disturbance term is then the stationary process $\kappa_{t}$. The solution of our model can then be written as a first-order dynamically stable vector autoregressive system with independently and identically distributed innovations. Analytical formulae for the second moments of the variables in our model are available in this case (see Hamilton, 1994, p. 265), and we use these to compute the loss function (10).

In the second set of experiments, there is a bubble. In this case, the model's solution includes a state variable $\left(z_{t}\right)$ which we model as follows:

$$
\begin{aligned}
z_{t}=\rho_{z} z_{t-1}+e_{z t}, \rho_{z}>0 & \\
\text { where } e_{z t} & =0, t=0, \ldots, t_{B U B-1} ; \\
e_{z t} & =0.01, t=t_{B U B} ; \\
e_{z t} & =0, t_{B U B}<t<t_{B U B+n} ; \\
e_{z t} & =-\left(\rho_{z}\right)^{n} e_{z t}, t_{B U B+n} ; \\
e_{z t} & =0, t>t_{B U B+n} .
\end{aligned}
$$

\footnotetext{
${ }^{8}$ Woodford finds that a forward-looking, optimization-based macroeconomic model provides support for a ratio of inflation (measured in quarterly units) to output gap loss function weights of 20:1, and contrasts this finding to studies that assign equal weights $a$ priori. Our setting of $\lambda \pi=\lambda y=1.0$ is actually quite consistent with Woodford's finding, since inflation is annualized in the objective function (10), implying a ratio of weights equal to $16: 1$ when inflation is expressed in quarterly units.
} 
Here, $t_{B U B}$ denotes the period in which the bubble commences $\left(z_{t}\right.$ becomes nonzero) and $t_{B U B+n}$ the period in which it bursts (i.e., $z_{t}$ returns to zero). We set $\rho_{z}=1.15$.

Specification (11) implies that when there is a bubble, the state vector ${ }^{9}$ contains an explosive time series process and includes a heteroskedastic process (the $e_{z t}$ sequence) in the vector of innovations. Analytical formulae for the model moments are no longer available in this case, and instead, we compute the value of (10) and other moments by taking averages across 600 stochastic simulations.

Finally, we need to specify the length of the bubble. Following Bernanke and Gertler (1999), we make the termination point of the bubble probabilistic. Specifically, we assume that the probability of the bubble lasting another period is 0.6. This implies that the maximum length of the bubble is approximately three years. To implement this probabilistic assumption in our stochastic simulations, we divide our 600 stochastic simulations into thirteen unequal amounts, each associated with the bubble terminating after $1,2, \ldots, 13$ periods. ${ }^{10}$ Because the probability of the bubble lasting 13 periods is smallest $\left(0.6^{12}\right)$, the percentage of the simulations in which the bubble lasts 13 periods is the lowest (indeed, of the 600 simulations, only one $\left(0.6^{12} * 600 \approx 1\right)$ has the bubble lasting this long).

There are two aspects of our bubble specification which are dictated by computational convenience, but which might well be relaxed in future work. First, the above formulation follows Bernanke and Gertler in making the termination point of the bubble exogenous. Monetary policy cannot therefore literally "prick" the bubble. But it can, if it wishes, attempt to offset the effect of the bubble on the exchange rate by moving $R_{t}$ to affect $q_{t}$, which is driven, through (3), by both fundamentals and the bubble. Whether such offsetting action - in the form of a response of monetary policy to $q_{t}$ movements-is desirable is what we wish to determine.

\footnotetext{
${ }^{9}$ And, therefore, the solution expressions for endogenous variables.

${ }^{10}$ I.e., $n=0,1, \ldots, 12$ in equation (11).
} 
Secondly, within each simulation of our model, agents forecast next period's value for the bubble as $\mathrm{E}_{z_{t+1}}=\rho_{z} z_{t}$. This is a rational expectation provided the commencement and termination dates of the bubble are completely unknown to agents. When the bubble has been zero, agents' expectation is that it will remain zero indefinitely; once it has commenced, their expectation is that it will grow explosively indefinitely. Within each simulation run of the model, therefore, agents do not take into account any probability of termination in forming their expectations of $z_{t}$. A generalization that allows agents to view the termination point probabilistically is desirable; we make a simple attempt at this in Section 5.1.

While this specification of the bubble process is in line with Bernanke and Gertler (1999), it does not produce a "rational bubble" in the sense of Blanchard and Watson (1982). In Blanchard and Watson's framework, a bubble emerges endogenously from the dynamics of rational expectations models. Their rational bubble is intimately related to the existence of multiple model solutions. By contrast, the solution algorithm that we employ is unable to produce rational bubbles of the Blanchard-Watson variety. It does, however, impose more economic structure than standard solution procedures. More precisely, in regions of the parameter space $\left(\phi_{\pi}, \rho_{R}, \phi_{q}, k\right)$ for rule (9) which generate multiple rational expectations equilibria-i.e., multiple dynamically stable solutions for the endogenous variables such as output, inflation, and the real exchange rate-we use the minimal state variable criterion of $\operatorname{McCallum}(1983,1999)$ to select a unique equilibrium. ${ }^{11}$ The loss function generated by the MSV equilibrium is then used to evaluate the rule's performance. This procedure also differs from that used in other investigations of the optimal feedback rule and the optimal feedback horizon. For example, Levin, Wieland, and Williams (LWW) (2000) discard any policy rule that generates multiple stable solutions. ${ }^{12}$ We believe that evaluating rules according to their associated MSV equilibrium is preferable because it employs more of the structure of the

\footnotetext{
11 "Dynamic stability" here refers to the coefficients on lagged dependent variables in the solution expressions for the endogenous variables, rather than to the dynamics of the exogenous variables, which are allowed to have unit or explosive roots in their autoregressive representations (and, indeed, do so for our bubble process $z_{t}$ ).

${ }^{12}$ Similarly, Amato and Laubach (2000) state that a "particularly pertinent" drawback with instrument rules such as (9) is that that they "oftentimes causes indeterminacy of rational expectations equilibrium."
} 
economic model on the solution procedure, while at the same time ensuring continuity in the loss function evaluations.

To see why, imagine that a rule like $R_{t}=1.5 \mathrm{E} \pi_{\mathrm{t}+1}$ was associated with a unique stable rational expectations solution, but $R_{t}=1.51 \mathrm{E} \pi_{t+1}$ generated multiple stable solutions. In this case, the MSV procedure would tend to select among the multiple solutions the one whose properties (solution coefficients for the endogenous variables, as well as impulse responses) were "close" to those of the $R_{t}=1.5 \mathrm{E}_{t} \pi_{t+1}$ case. The alternative procedure used by LWW for example, would automatically discard all of the solutions (and loss functions) associated with a response coefficient greater than 1.5. This seems undesirable because it leaves unsettled the issue of what is the economically relevant solution when multiple solutions arise.

\section{Results}

We first present results on the performance of rule (9) applied to our model when the rule parameters are the same as those used in Bernanke and Gertler (1999). In particular, following Bernanke and Gertler, we present results with rule (9) when the forecast of inflation to which monetary policy responds is held at $k=1$ quarter, when the response coefficient $\phi_{\pi}$ in (9) is set to either 1.01 or 2.0, and when the response to (log) asset prices (stock prices in their case) is set to 0.10. Because nominal and real interest rates are expressed in quarterly rather than annualized units in our model, Bernanke and Gertler's asset price response of 0.10 corresponds to a value of $\phi_{q}=0.025$ in rule (9). For simplicity, Bernanke and Gertler do not consider interest rate smoothing; however, we do include smoothing cases (i.e., $\rho_{R}>0$ in (9)) in our experiments below.

Results with Bernanke and Gertler's parameterizations of rule (9) are reported for our model in Table 2, both for "no-bubble" cases and for cases where there is a bubble. As discussed in Section 3, the no-bubble case corresponds to the case $z_{t}=0$ for all $t$ in 
equation (3). Thus, IS, Phillips curve, and "normal-sized" UIP shocks (the $\kappa_{t}$ process in eq. (3)) are hitting the economy in these experiments, but there are no bubble episodes. ${ }^{13}$

No bubble, no optimization of response coefficients

Consider the no-bubble cases first. Table 2 indicates that, in our model, as in Bernanke and Gertler (1999), a nominal interest rate response of 2.0 to next period's expected inflation rate is superior to a response of 1.01 for both inflation and output gap control. Once a smoothing term is included, the coefficients on expected inflation should be interpreted as short-run coefficients; for example, the rule $R_{t}=1.01 \mathrm{E}_{t} \pi_{t+1}+0.9 R_{t-1}$ implies a long-run response of 10.1 to inflation. The rules with smoothing terms dominate the corresponding rules without smoothing. This is not so much because they reduce interest rate volatility (as measured by $\sigma\left(4 * \Delta R_{t}\right)$ ) but because they reduce inflation variability without much cost in output variability. ${ }^{14}$ The effect of the inclusion of the interest rate variability term in (10) on these results is, instead, to keep down the optimal value of $\phi_{\pi}$ in (9). The optimal value of $\phi_{\pi}$ would take very high double-digit values if the interest rate variability term were dropped from (10).

As Table 2 shows, adding a small response of 0.025 to the real exchange rate to produce the rule $R_{t}=1.01 \mathrm{E} \pi_{t+1}+0.9 R_{t-1}+0.025 q_{t-1}$ delivers the best welfare outcome in the table. The loss function in this case is 17.36 , a small improvement over the 17.49 loss recorded without the exchange rate response. Larger exchange rate responses (e.g. 0.05), however, reduce welfare (producing a loss of 17.65), relative to the zero-response case.

\footnotetext{
${ }^{13}$ It is important to note that because the loss function is expressed in variances, differences in the performances of alternative rules that seem small when given in percentage standard deviations of variables can translate into quite large differences in loss function values. For this reason, we do not compare alternative loss function values by taking ratios of the two.

${ }^{14}$ The latter property of rules with interest rate smoothing in forward-looking models has been emphasized by Rotemberg and Woodford (1999).
} 


\begin{tabular}{|c|c|c|c|c|c|}
\hline \multicolumn{6}{|c|}{$\begin{array}{l}\text { Table 2: One-period-ahead inflation forecast based rules } \\
\text { (coefficients not optimized) }\end{array}$} \\
\hline \multicolumn{6}{|c|}{ Results with No Bubble } \\
\hline & $\sigma\left(4^{*} \pi\right)$ & $\sigma(y)$ & $\sigma(4 * \Delta R)$ & $\sigma(q)$ & Loss \\
\hline$R_{t}=1.01 \mathrm{E}_{t} \pi_{t+1}$ & 12.22 & 1.93 & 2.77 & 5.37 & 156.89 \\
\hline$R_{t}=2.0 \mathrm{E} \pi_{t+1}$ & 4.02 & 1.76 & 4.22 & 4.59 & 28.15 \\
\hline$R_{t}=1.01 \mathrm{E}_{t} \pi_{t+1}+0.9 R_{t-1}$ & 3.22 & 2.12 & 2.30 & 5.79 & 17.49 \\
\hline$R_{t}=2.0 \mathrm{E}_{t} \pi_{t+1}+0.9 R_{t-1}$ & 2.94 & 2.18 & 3.81 & 6.34 & 20.63 \\
\hline$R_{t}=1.01 \mathrm{E}_{t} \pi_{t+1}+0.025 q_{t-1}$ & 12.56 & 1.83 & 2.79 & 4.89 & 165.07 \\
\hline$R_{t}=2.0 \mathrm{E} \pi_{t+1}+0.025 q_{t-1}$ & 4.06 & 1.74 & 4.28 & 4.42 & 28.72 \\
\hline$R_{t}=1.01 \mathrm{E} \pi_{t+1}+0.9 R_{t-1}+0.025 q_{t-1}$ & 3.26 & 2.04 & 2.28 & 5.30 & 17.36 \\
\hline$R_{t}=2.0 \mathrm{E} \pi_{t+1}+0.9 R_{t-1}+0.025 q_{t-1}$ & 2.95 & 2.13 & 3.78 & 6.02 & 20.40 \\
\hline$R_{t}=1.01 \mathrm{E}_{t} \pi_{t+1}+0.9 R_{t-1}+0.050 q_{t-1}$ & 3.33 & 1.98 & 2.30 & 4.90 & 17.65 \\
\hline \multicolumn{6}{|c|}{ Results with Bubble Operative } \\
\hline$R_{t}=1.01 \mathrm{E} \pi_{t+1}$ & 12.15 & 1.95 & 2.77 & 5.38 & 155.25 \\
\hline$R_{t}=2.0 \mathrm{E}_{t} \pi_{t+1}$ & 4.09 & 1.78 & 4.28 & 4.66 & 29.16 \\
\hline$R_{t}=1.01 \mathrm{E}_{t} \pi_{t+1}+0.9 R_{t-1}$ & 3.42 & 2.17 & 2.59 & 7.80 & 19.84 \\
\hline$R_{t}=2.0 \mathrm{E} \pi_{t+1}+0.9 R_{t-1}$ & 3.08 & 2.18 & 4.28 & 10.39 & 23.43 \\
\hline$R_{t}=1.01 \mathrm{E}_{t} \pi_{t+1}+0.025 q_{t-1}$ & 12.81 & 1.86 & 2.80 & 4.96 & 171.48 \\
\hline$R_{t}=2.0 \mathrm{E} \pi_{t+1}+0.025 q_{t-1}$ & 4.13 & 1.77 & 4.35 & 4.51 & 29.66 \\
\hline$R_{t}=1.01 \mathrm{E} \pi_{t+1}+0.9 R_{t-1}+0.025 q_{t-1}$ & 3.51 & 2.07 & 3.06 & 10.41 & 21.30 \\
\hline$R_{t}=2.0 \mathrm{E} \pi_{t+1}+0.9 R_{t-1}+0.025 q_{t-1}$ & 3.14 & 2.17 & 4.88 & 13.68 & 26.46 \\
\hline$R_{t}=1.01 \mathrm{E}_{t} \pi_{t+1}+0.9 R_{t-1}+0.050 q_{t-1}$ & 16.96 & 10.53 & 42.34 & 177.34 & 1294.8 \\
\hline \multicolumn{6}{|c|}{$\begin{array}{l}\text { Note: For the no-bubble case, standard deviations and loss function values are obtained } \\
\text { using analytical formulae for the vector autoregressive representation of the solution of } \\
\text { the model. For the operative-bubble cases, these moments and losses reported are the } \\
\text { averages across stochastic simulations, as described in Section 3. The standard deviation } \\
\text { of the real exchange rate is reported as a memo item only; there is no exchange rate term } \\
\text { in the loss function (10). }\end{array}$} \\
\hline
\end{tabular}


Bubble operative, no optimization of response coefficients

What happens when the bubble is operative? In this case, as Table 2 shows, the rules with a nonzero response to the exchange rate deliver unambiguously poorer welfare outcomes. Indeed, the last row shows that a response of 0.05 produces a calamitous increase in the loss function to 1294.8 compared to 19.84 for the corresponding rule with a zero response. A moderate response of 0.025 to the exchange rate does appear to reduce output gap variability, but the impact of this improvement on the loss function is swamped by the rise in inflation and interest rate variability. So compared to the nobubble case, the results suggest that the presence of the bubble tends to raise loss functions, but that attempting to reduce the bubble's effects on the exchange rate magnifies the increase in loss.

In uncovering the reason for these results, one should distinguish between two cases: (i) responding to $q_{t-1}$ and with no interest rate smoothing; and (ii) responding to both $q_{t-1}$ and $R_{t-1}$. Provided there is no smoothing, responding to $q_{t-1}$ does tend to reduce the variability of the real exchange rate. For example, with the bubble, Table 2 indicates that the rule $R_{t}=1.01 \mathrm{E} \pi_{t+1}$ produces $\sigma\left(q_{t}\right)=5.38 \%$, while the rule $R_{t}=1.01 \mathrm{E}_{t} \pi_{t+1}+0.025$ $q_{t-1}$ reduces $\sigma\left(q_{t}\right)$ to $4.51 \%$. This reduction in exchange rate volatility is also associated with a reduction in output gap volatility, but the favorable effect of this on the loss function is offset by higher inflation variability.

When there is smoothing, however, $\phi_{q}>0$ actually increases the variability of $q_{t}$ when a bubble is present. For example, the rule $\left\{\phi_{\pi}=1.01, \rho_{R}=0.9, \phi_{q}=0\right\}$ yields $\sigma\left(q_{t}\right)=$ $7.80 \%$ in Table 2, but $\left\{\phi_{\pi}=1.01, \rho_{R}=0.9, \phi_{q}=0.025\right\}$ gives $\sigma\left(q_{t}\right)=10.41 \%$. The reason why responding to the exchange rate has a perverse effect on exchange rate variability appears to be the associated expectations of future interest rate changes. With $\rho_{R}>0$ and $\phi_{q}>0$, it is known that the long-run response of the interest rate to an exchange rate movement will be greater than the initial response. Furthermore, due to the explosiveness of the $z_{t}$ process, a bubble innovation will (for a given policy response) 


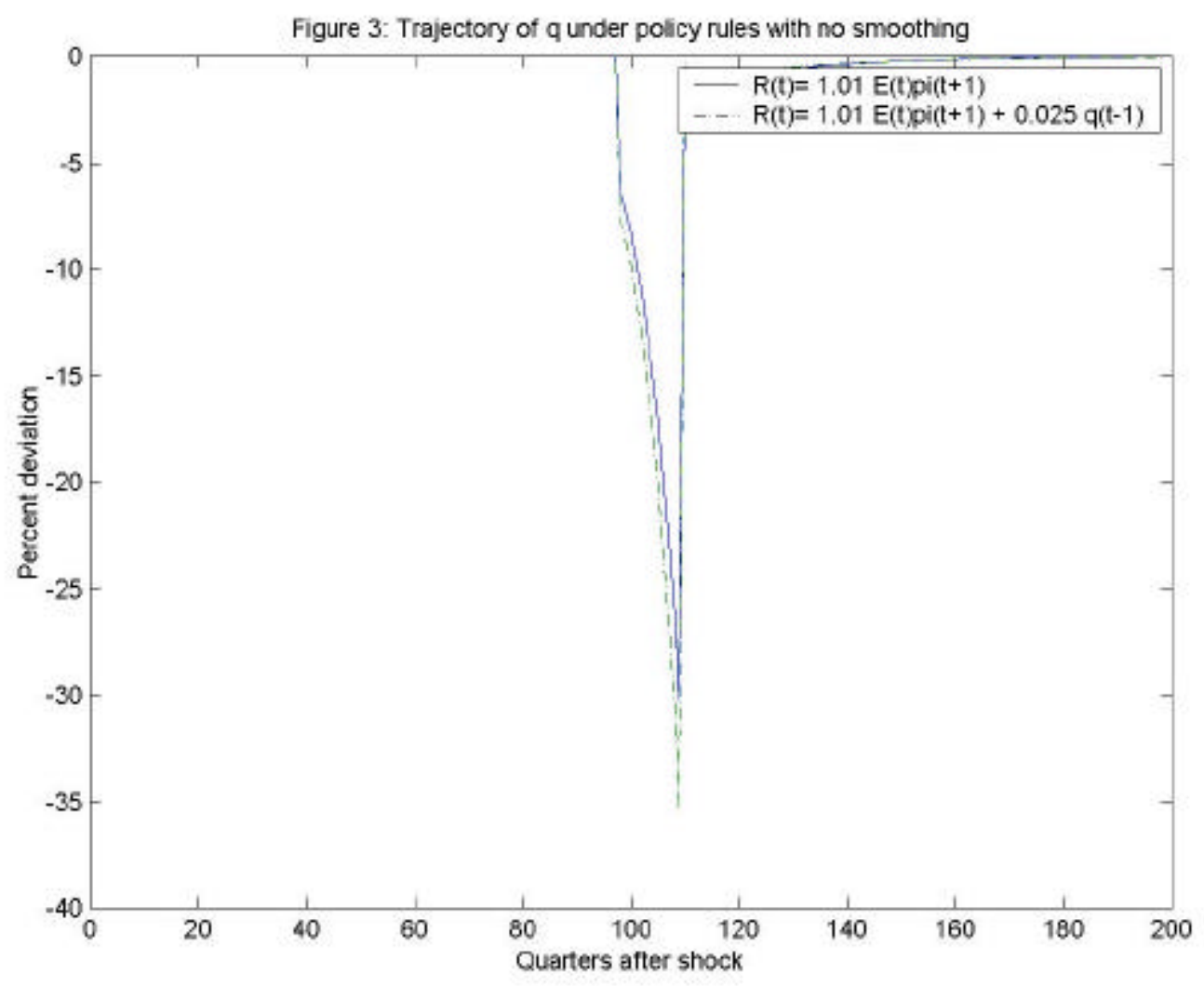

have a greater impact in the future than today. For both these reasons, the fall in the interest rate in response to a bubble shock is expected to be greater in the future than it is today. This has a destabilizing effect on exchange rate expectations, creating anticipations of an explosive depreciation. So while the interest rate response is successful in offsetting the impact of the bubble-whose effect alone would be to produce exchange rate appreciation-policy succeeds in doing so at the cost of promoting an unbounded depreciation.

Some graphical insight into these points is provided by Figures 3 and 4. These depict the path of $q_{t}$ from a simulation that sets the bubble length to 12 periods and suppresses the IS, Phillips curve, and stationary UIP shocks, so that the only source of variability is the bubble. ${ }^{15}$ Figure 3 gives the path of $q_{t}$ when $\rho_{R}=0$ (no smoothing). The bubble tends to produce an explosive appreciation, and the policy rule is able to restrain but not prevent

\footnotetext{
${ }^{15}$ It thus differs from the simulations whose results are reported in the tables; these always have IS, Phillips curve, and stationary UIP shocks operating alongside the bubble shock.
} 


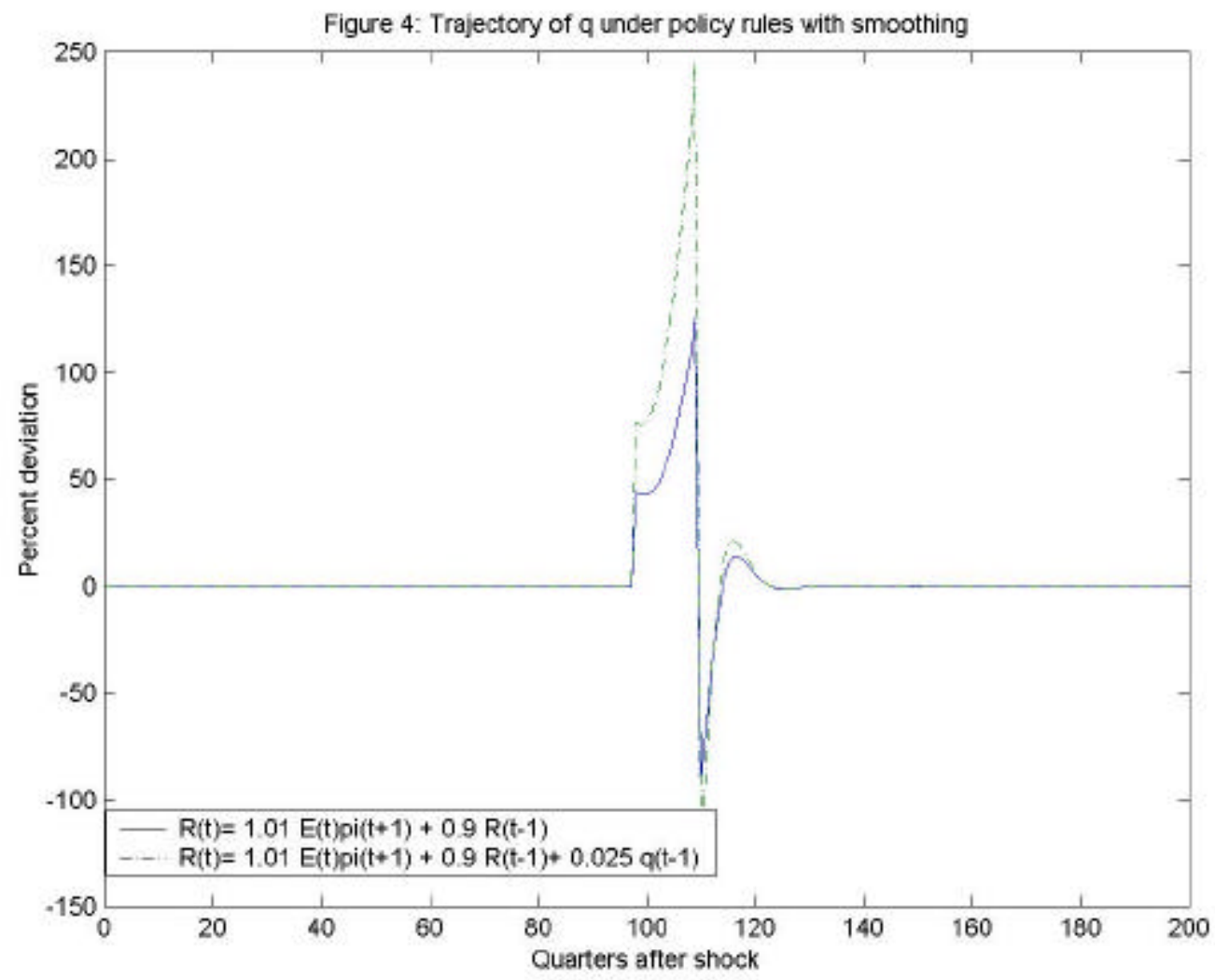

this appreciation (solid line). Once the bubble bursts, the exchange rate returns quickly to its steady-state value. As the dashed line shows, an explicit exchange rate response $\left(\phi_{q}>0\right)$ is counterproductive as it reinforces the appreciation, but its overall effect is small.

Figure 4 above gives the corresponding $q_{t}$ paths with $\rho_{R}=0.9$. Interest rate smoothing gives agents signals about future interest rates, which then affect the current exchange rate through the UIP condition (3). Because they induce expectations of unbounded future falls in interest rates, ${ }^{16}$ these policy rules are successful at stopping the forces for appreciation that the bubble creates, but do so at the cost of producing an explosive depreciation. With the bursting of the bubble, expectations of interest rate declines abruptly come to a halt, and the exchange rate plunges below its steady-state value.

\footnotetext{
${ }^{16}$ Our model does not impose a zero lower bound on nominal interest rates. If this were imposed, there would be a limit to expectations of falls in nominal interest rates in response to a bubble shock. But if we changed the sign of our initial bubble shock, rules with interest rate smoothing would promote expectations
} 
These oscillations are considerably worse when there is a nonzero exchange rate response in the policy rule.

\section{No bubble, optimized response coefficients}

In Table 2 we found that while responding to the exchange rate damaged welfare in several cases, the lowest loss function value in the no-bubble experiments was obtained with a rule that did include a nonzero response to the exchange rate. However, viewed as special cases of the feedback rule (9), the rules examined in Table 2 may not be informative about the overall welfare picture, because none of the parameters in the rules were optimized. Rather, the inflation response $\phi_{\pi}$, the exchange rate response $\phi_{q}$, and the horizon $k$ were fixed at the values considered by Bernanke and Gertler, and the smoothing parameter $\rho_{R}$ was set at arbitrary values. In Table 3, we rectify this problem and report the results of optimized versions of rule (9). The results for the optimal horizon $k$ are obtained by searching over $k=0, \ldots, 10 .^{17}$

Again, let us focus first on the no-bubble scenario. When the horizon is fixed at $k=1$, it is optimal to respond to the real exchange rate as well as expected inflation, although the optimal response coefficient is quite low $\left(\phi_{q}=0.022\right)$. However, this is not a fully optimal version of rule (9) due to the horizon $k$ not being optimized. When it is optimized, together with the other coefficients, the resulting rule is $R_{t}=1.34 \mathrm{E} \pi_{t+2}+$ $1.00 R_{t-1}+0.00 q_{t-1}$, identical to the rule obtained when $\phi_{q}=0$ was imposed. ${ }^{18}$ In other words, it is not optimal, in the bubble-free version of our model, to incorporate any separate response to the exchange rate. When the inflation feedback horizon and the coefficient associated with it have been chosen optimally, it appears desirable to respond

of unbounded increases in interest rates, and the zero lower bound would not put a limit on these expectations.

${ }^{17}$ We previously found optimal values of $\phi_{\pi}, \rho_{R}$, and $k$ with the model used here (Batini and Nelson, 2000), but we used a different value for the Phillips curve innovation variance. Therefore, we need to reoptimize the parameters in (9) in light of the parameterization of the model that we are using in this paper. In addition, of course, we set $\phi_{q}=0$ in our previous work, while now we wish to find the optimal value of $\phi_{q}$. 
to exchange rates only indirectly, and to the extent that they affect the conditional expectation of inflation at that horizon. This is in line with Bernanke and Gertler's (1999, p. 78) recommendation that "policy should not respond to changes in asset prices, except insofar as they signal changes in expected inflation."

By contrast, CGLW (2000) found that in our model when the economy is subjected only to stationary UIP shocks (the $\kappa_{t}$ process in (3), with $z_{t}=0$ ), a nonzero response to the exchange rate improves welfare compared to our optimized rule in Batini and Nelson (2000). The major reason we do not reproduce that result is that our simulations include IS and Phillips curve shocks, which were not present in the CGLW experiments; responding to exchange rates is welfare-reducing when these shocks are permitted to coexist with risk premium shocks.

\section{Bubble operative, optimized response coefficients}

We now report results from simulations that add the bubble process. Three types of results are presented: $(a)$ the performance in this environment of rules of the form (9) that were optimized for the no-bubble case; $(b)$ the effect on these rules' performance of adding an arbitrary exchange rate response; $(c)$ a re-optimized version of (9) with the coefficients (including $\phi_{q}$ ) optimized according to minimizing average welfare across the 600 stochastic simulations under bubble conditions.

As Table 3 shows, the rule $\left\{\phi_{\pi}=1.34, \rho_{R}=1.0\right\}$ gives somewhat poorer inflation and interest rate outcomes than it did in the no-bubble case, but the outcomes are still respectable. If we simply add a 0.025 response of the nominal interest rate to $q_{t-1}$, the variability of all three components of the objective function increases, and overall welfare is $50 \%$ worse.

\footnotetext{
${ }^{18}$ This rule is in turn very close to that we found in Batini and Nelson (2000), which was $1.24 \mathrm{E}_{1} \pi_{t+2}+0.98$ $R_{t-1}$. The lower value for the Phillips curve shock standard deviation that we use here is the source of the small differences.
} 
Table 3: Forecast based rules: coefficients and horizons optimized

\begin{tabular}{|c|c|c|c|c|}
\hline & \multicolumn{3}{|c|}{ Standard deviations } & \multirow[b]{2}{*}{ Loss } \\
\hline & $\sigma(4 * \pi)$ & $\sigma(y)$ & $\sigma\left(4^{*} \Delta R\right)$ & \\
\hline \multicolumn{5}{|c|}{ Results with No Bubble } \\
\hline \multicolumn{5}{|l|}{$\begin{array}{l}\text { Rule }(9), \phi_{\pi} \text { and } \rho_{R} \text { optimized, } \phi_{q}=0 \\
\text { imposed, horizon fixed at } k=1 \text { quarter: }\end{array}$} \\
\hline$R_{t}=0.88 \mathrm{E} \pi_{t+1}+0.87 R_{t-1}$ & 3.30 & 2.08 & 2.08 & 17.3685 \\
\hline \multicolumn{5}{|l|}{$\begin{array}{l}\text { Rule (9), } \phi_{\pi} \text { and } \rho_{R} \text { and } \phi_{q} \text { optimized, } \\
\text { horizon fixed at } k=1 \text { quarter: }\end{array}$} \\
\hline$R_{t}=0.83 \mathrm{E}_{t} \pi_{t+1}+0.93 R_{t-1}+0.024 q_{t-1}$ & 3.30 & 2.05 & 2.05 & 17.2021 \\
\hline \multicolumn{5}{|l|}{$\begin{array}{l}\text { Rule (9), } \phi_{\pi} \text { and } \rho_{R} \text { and } \phi_{q} \text { optimized, } \\
\phi_{q}=0 \text { imposed, horizon optimized }\end{array}$} \\
\hline$R_{t}=1.34 \mathrm{E}_{t} \pi_{t+2}+1.00 R_{t-1}$ & 3.30 & 2.04 & 2.04 & 17.1527 \\
\hline \multicolumn{5}{|l|}{$\begin{array}{l}\text { Rule }(9), \phi_{\pi} \text { and } \rho_{R} \text { and } \phi_{q} \text { optimized, } \\
\text { horizon optimized }\end{array}$} \\
\hline$R_{t}=1.34 \mathrm{E}_{t} \pi_{t+2}+1.00 R_{t-1}+0.00 q_{t-1}$ & 3.30 & 2.04 & 2.04 & 17.1527 \\
\hline \multicolumn{5}{|c|}{ Results with Bubble Operative } \\
\hline$R_{t}=1.34 \mathrm{E}_{t} \pi_{t+2}+1.00 R_{t-1}$ & 3.57 & 2.07 & 2.81 & 20.98 \\
\hline$R_{t}=1.34 \mathrm{E}_{t} \pi_{t+2}+1.00 R_{t-1}+0.025 q_{t-1}$ & 3.97 & 2.16 & 4.55 & 31.01 \\
\hline \multicolumn{5}{|l|}{$\begin{array}{l}\text { Rule }(9), \phi_{\pi}, \rho_{R} \text { and } \phi_{q} \text { optimized, } \\
\phi_{q}=0 \text { imposed, horizon optimized: }\end{array}$} \\
\hline$R_{t}=1.21 \mathrm{E}_{t} \pi_{t+2}+0.86 R_{t-1}$ & 3.53 & 1.96 & 2.38 & 19.15 \\
\hline \multicolumn{5}{|l|}{$\begin{array}{l}\text { Rule (9), } \phi_{\pi} \text { and } \rho_{R} \text { optimized, } \phi_{q}=0 \\
\text { imposed, horizon fixed at } k=1 \text { quarter: }\end{array}$} \\
\hline$R_{t}=0.87 \mathrm{E}_{t} \pi_{t+1}+0.87 R_{t-1}$ & 3.48 & 2.13 & 2.27 & 19.27 \\
\hline \multicolumn{5}{|l|}{$\begin{array}{l}\text { Rule (9), } \phi_{\pi} \text { and } \rho_{R} \text { and } \phi_{q} \text { optimized, } \\
\text { horizon fixed at } k=1 \text { quarter: }\end{array}$} \\
\hline$R_{t}=0.87 \mathrm{E}_{t} \pi_{t+1}+0.87 R_{t-1}+0.00 q_{t-1}$ & 3.48 & 2.13 & 2.27 & 19.27 \\
\hline \multicolumn{5}{|l|}{$\begin{array}{l}\text { Optimal feedback rule with expected } \\
\text { inflation, smoothing, and exchange rate } \\
\text { response, all coefficients optimized, } \\
\text { horizon optimized }\end{array}$} \\
\hline$R_{t}=1.21 \mathrm{E}_{t} \pi_{t+2}+0.86 R_{t-1}+0.00 q_{t-1}$ & 3.53 & 1.96 & 2.38 & 19.15 \\
\hline
\end{tabular}


The third rule reported in the "bubble operative" cases in Table 3 is one for which the response coefficients and horizon have been optimized. Relative to the no-bubble case, the optimal values of $\rho_{R}$ and $\phi_{\pi}$ are lower, the optimal feedback horizon is unchanged at $k$ $=2$, and the optimal exchange rate response remains zero. Thus the bubble does alter the optimal parameterization of rule (9), but not in a manner that is supportive of a nonzero response to asset prices. The sharply lower value of $\rho_{R}$ is probably optimal because it reduces the destabilizing effect on the exchange rate that interest rate smoothing has when the bubble is operative, discussed earlier.

Table 3 also indicates that if a horizon of $k=1$ is imposed and the coefficients are reoptimized, there is still no support for $\phi_{q}>0$. The presence of the bubble therefore reduces the case for $\phi_{q}>0$, just as it did in Table 2 .

One possible reason why a response to $q_{t-1}$ does not seem desirable in Table 3 is that in the structural model only the four-quarter average of $q$, i.e. $\tilde{q}$, matters for demand and inflation. Tables 4 and 5 investigate this issue by contemplating rules where $\tilde{q}_{t-1}$ rather than $q_{t-1}$ appears in rule (9), i.e. the longer-term, economically relevant average of the real exchange rate is the asset price that is allowed to enter the rule.

Responding to the economically relevant exchange rate concept does produce an improvement over responding to a simple one-period lag of $q_{t}$. This can be verified by noting that all the losses reported in Tables 4 and 5 are lower than the losses from the corresponding rules in Tables 2 and 3 that used $q_{t-1}$ instead of $\tilde{q}_{t-1}$. However, once the coefficients and feedback horizon for the expected inflation rate in the policy rule are optimized, Table 5 indicates that there is no welfare gain from responding to $\tilde{q}_{t-1}$ : the best rules (both with and without the bubble) are the same as those found in Table 3, and involve a zero response to the exchange rate.

Finally, for comparison we report, in Tables 6 and 7, results using a model in which the exchange rate figures more prominently, namely our model but with the Phillips curve (2) 
Table 4: One-period-ahead inflation forecast based rule with annual average of exchange rate in rule

(coefficients not optimized)

\begin{tabular}{|c|c|c|c|c|}
\hline & \multicolumn{3}{|c|}{ Standard deviations } & \multirow[b]{2}{*}{ Loss } \\
\hline & $\sigma\left(4^{*} \pi\right)$ & $\sigma(y)$ & $\sigma\left(4^{*} \Delta R\right)$ & \\
\hline \multicolumn{5}{|c|}{ Results with No Bubble } \\
\hline$R_{t}=1.01 \mathrm{E}_{t} \pi_{t+1}+0.025 \tilde{q}_{t-1}$ & 12.34 & 1.80 & 2.76 & 159.32 \\
\hline$R_{t}=2.0 \mathrm{E}_{t} \pi_{t+1}+0.025 \tilde{q}_{t-1}$ & 4.06 & 1.74 & 4.26 & 28.548 \\
\hline$R_{t}=1.01 \mathrm{E} \pi_{t+1}+0.9 R_{t-1}+0.025 \tilde{q}_{t-1}$ & 3.22 & 2.05 & 2.36 & 17.35 \\
\hline$R_{t}=2.0 \mathrm{E} \pi_{t+1}+0.9 R_{t-1}+0.025 \tilde{q}_{t-1}$ & 2.93 & 2.14 & 3.88 & 20.68 \\
\hline$R_{t}=1.01 \mathrm{E}_{t} \pi_{t+1}+0.9 R_{t-1}+0.050 \tilde{q}_{t-1}$ & 3.27 & 1.99 & 2.42 & 17.55 \\
\hline \multicolumn{5}{|c|}{$\begin{array}{ll}\text { Results with Bubble Operative } \\
\end{array}$} \\
\hline$R_{t}=1.01 \mathrm{E}_{t} \pi_{t+1}+0.025 \tilde{q}_{t-1}$ & 12.37 & 1.83 & 4.94 & 160.19 \\
\hline$R_{t}=2.0 \mathrm{E} \pi_{t+1}+0.025 \tilde{q}_{t-1}$ & 4.11 & 1.76 & 4.31 & 29.18 \\
\hline$R_{t}=1.01 \mathrm{E} \pi_{t+1}+0.9 R_{t-1}+0.025 \tilde{q}_{t-1}$ & 3.50 & 2.09 & 2.95 & 20.98 \\
\hline$R_{t}=2.0 \mathrm{E} \pi_{t+1}+0.9 R_{t-1}+0.025 \tilde{q}_{t-1}$ & 3.15 & 2.17 & 4.76 & 25.98 \\
\hline$R_{t}=1.01 \mathrm{E} \pi_{t+1}+0.9 R_{t-1}+0.050 \tilde{q}_{t-1}$ & 4.56 & 2.30 & 5.26 & 39.88 \\
\hline
\end{tabular}

Note: See notes to Table 2. 
Table 5: Forecast based rules: coefficients and horizons optimized with annual average of exchange rate in rule

\begin{tabular}{|c|c|c|c|c|}
\hline & \multicolumn{3}{|c|}{ Standard deviations } & \multirow[b]{2}{*}{ Loss } \\
\hline & $\sigma(4 * \pi)$ & $\sigma(y)$ & $\sigma\left(4^{*} \Delta R\right)$ & \\
\hline \multicolumn{5}{|c|}{ Results with No Bubble } \\
\hline$R_{t}=1.34 \mathrm{E} \pi_{t+2}+1.00 R_{t-1}+0.025 \tilde{q}_{t-1}$ & 3.31 & 2.00 & 2.11 & 17.16 \\
\hline$R_{t}=1.21 \mathrm{E}_{t} \pi_{t+2}+0.86 R_{t-1}+0.025 \tilde{q}_{t-1}$ & 3.45 & 1.91 & 2.08 & 17.70 \\
\hline \multicolumn{5}{|l|}{$\begin{array}{l}\phi_{\pi}, \rho_{R} \text { and } \phi_{q} \text { optimized, horizon fixed at } \\
k=1 \text { quarter: }\end{array}$} \\
\hline$R_{t}=0.83 \mathrm{E}_{t} \pi_{t+1}+0.93 R_{t-1}+0.024 \tilde{q}_{t-1}$ & 3.30 & 2.05 & 2.05 & 17.20 \\
\hline \multicolumn{5}{|l|}{$\phi_{\pi}, \rho_{R}$ and $\phi_{q}$ optimized, horizon optimized: } \\
\hline$R_{t}=1.34 \mathrm{E} \pi_{t+2}+1.00 R_{t-1}+0.00 \tilde{q}_{t-1}$ & 3.30 & 2.04 & 2.04 & 17.15 \\
\hline \multicolumn{5}{|c|}{ Results with Bubble Operative } \\
\hline$R_{t}=1.34 \mathrm{E}_{t} \pi_{t+2}+1.00 R_{t-1}+0.025 \tilde{q}_{t-1}$ & 3.86 & 2.34 & 4.52 & 30.62 \\
\hline$R_{t}=1.21 \mathrm{E}_{t} \pi_{t+2}+0.86 R_{t-1}+0.025 \tilde{q}_{t-1}$ & 3.36 & 2.05 & 3.21 & 20.66 \\
\hline \multicolumn{5}{|l|}{$\begin{array}{l}\phi_{\pi}, \rho_{R} \text { and } \phi_{q} \text { optimized, horizon fixed at } \\
k=1 \text { quarter: }\end{array}$} \\
\hline$R_{t}=0.87 \mathrm{E}_{t} \pi_{t+1}+0.87 R_{t-1}+0.00 \tilde{q}_{t-1}$ & 3.48 & 2.13 & 2.27 & 19.27 \\
\hline \multicolumn{5}{|l|}{$\phi_{\pi}, \rho_{R}$ and $\phi_{q}$ optimized, horizon optimized } \\
\hline$R_{t}=1.21 \mathrm{E}_{t} \pi_{t+2}+0.86 R_{t-1}+0.00 \tilde{q}_{t-1}$ & 3.53 & 1.96 & 2.38 & 19.15 \\
\hline
\end{tabular}




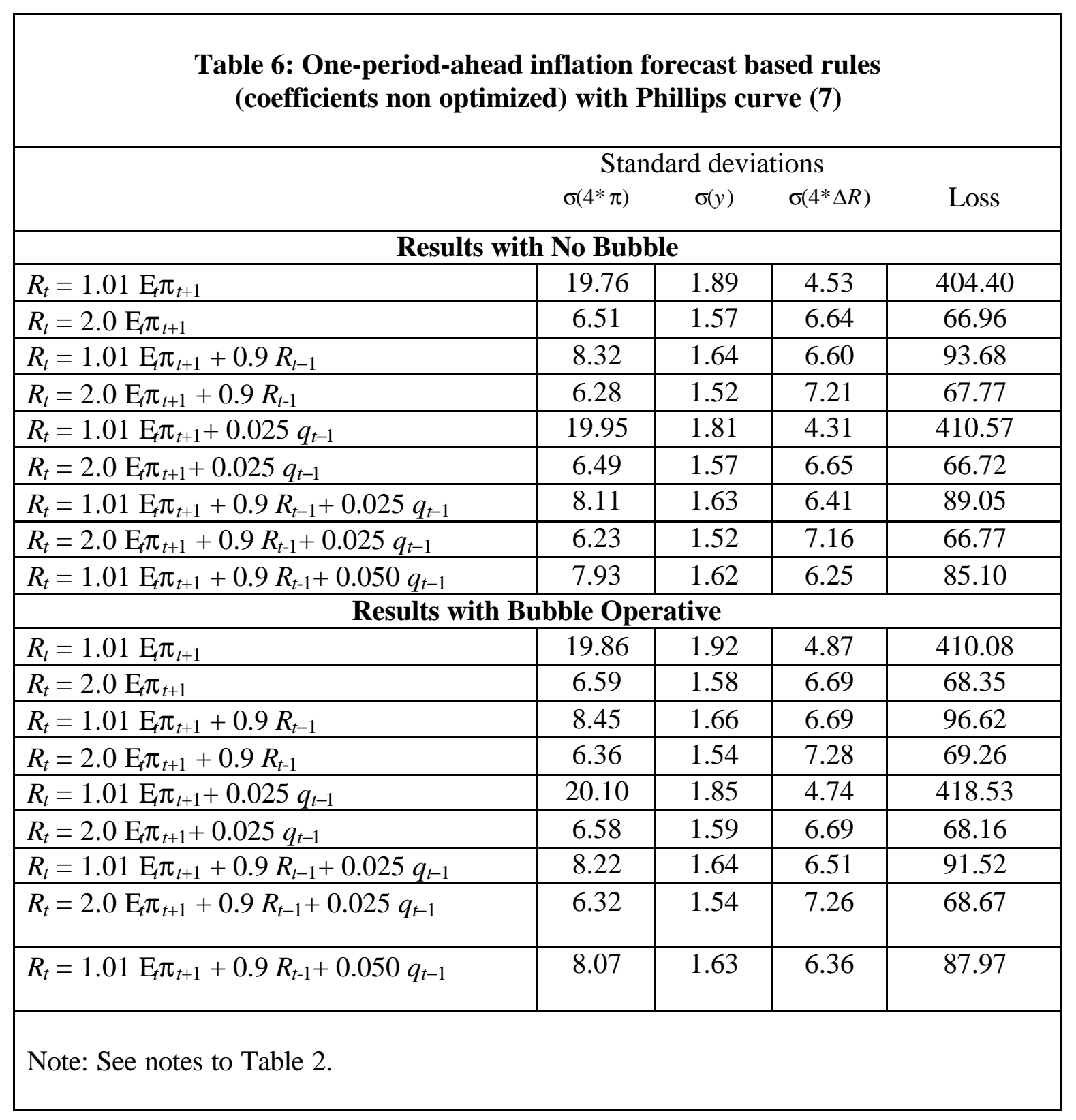


Table 7: Forecast based rules: coefficients and horizons optimized Phillips curve (7) used

\begin{tabular}{|c|c|c|c|c|}
\hline \multicolumn{5}{|c|}{ Standard deviations } \\
\hline & $\sigma(4 * \pi)$ & $\sigma(y)$ & $\sigma\left(4^{*} \Delta R\right)$ & Loss \\
\hline \multicolumn{5}{|c|}{ Results with No Bubble } \\
\hline \multicolumn{5}{|l|}{$\begin{array}{l}\text { Rule }(9), \phi_{\pi} \text { and } \rho_{R} \text { optimized, } \phi_{q}=0 \\
\text { imposed, horizon fixed at } k=1 \text { quarter: }\end{array}$} \\
\hline$R_{t}=2.01 \mathrm{E}_{t} \pi_{t+1}+0.43 R_{t-1}$ & 6.04 & 1.54 & 6.78 & 61.83 \\
\hline \multicolumn{5}{|l|}{$\begin{array}{l}\text { Rule (9), } \phi_{\pi}, \rho_{R} \text { and } \phi_{q} \text { optimized, horizon } \\
\text { fixed at } k=1 \text { quarter: }\end{array}$} \\
\hline$R_{t}=1.61 \mathrm{E}_{t} \pi_{t+1}+0.62 R_{t-1}+0.35 q_{t-1}$ & 6.12 & 1.55 & 6.08 & 58.30 \\
\hline \multicolumn{5}{|l|}{$\begin{array}{l}\text { Rule (9), } \phi_{\pi}, \rho_{R} \text { and } \phi_{q} \text { optimized, } \phi_{q}=0 \\
\text { imposed, horizon optimized }\end{array}$} \\
\hline$R_{t}=3.64 \mathrm{E}_{t} \pi_{t+2}+0.43 R_{t-1}$ & 6.05 & 1.52 & 6.10 & 57.47 \\
\hline \multicolumn{5}{|l|}{$\begin{array}{l}\text { Rule (9), } \phi_{\pi}, \rho_{R} \text { and } \phi_{q} \text { optimized, horizon } \\
\text { optimized }\end{array}$} \\
\hline$R_{t}=2.96 \mathrm{E} \pi_{t+2}+0.55 R_{t-1}+0.19 q_{t-1}$ & 6.09 & 1.54 & 5.94 & 57.08 \\
\hline \multicolumn{5}{|c|}{ Results with Bubble Operative } \\
\hline \multicolumn{5}{|l|}{$\begin{array}{l}\text { Rule (9), } \phi_{\pi} \text { and } \rho_{R} \text { optimized, } \phi_{q}=0 \\
\text { imposed, horizon fixed at } k=1 \text { quarter: }\end{array}$} \\
\hline$R_{t}=2.04 \mathrm{E}_{t} \pi_{t+1}+0.33 R_{t-1}$ & 6.13 & 1.56 & 6.81 & 63.21 \\
\hline \multicolumn{5}{|l|}{$\begin{array}{l}\text { Rule (9), } \phi_{\pi}, \rho_{R} \text { and } \phi_{q} \text { optimized, horizon } \\
\text { fixed at } k=1 \text { quarter: }\end{array}$} \\
\hline$R_{t}=1.49 \mathrm{E}_{t} \pi_{t+1}+0.60 R_{t-1}+0.35 q_{t-1}$ & 6.24 & 1.58 & 5.89 & 58.82 \\
\hline \multicolumn{5}{|l|}{$\begin{array}{l}\text { Rule (9), } \phi_{\pi}, \rho_{R} \text { and } \phi_{q} \text { optimized, } \phi_{q}=0 \\
\text { imposed, horizon optimized }\end{array}$} \\
\hline$R_{t}=3.50 \mathrm{E}_{t} \pi_{t+2}+0.40 R_{t-1}$ & 6.11 & 1.54 & 6.07 & 58.08 \\
\hline \multicolumn{5}{|l|}{$\begin{array}{l}\text { Rule (9), } \phi_{\pi}, \rho_{R} \text { and } \phi_{q} \text { optimized, horizon } \\
\text { optimized }\end{array}$} \\
\hline$R_{t}=2.80 \mathrm{E} \pi_{t+2}+0.50 R_{t-1}+0.20 q_{t-1}$ & 6.13 & 1.55 & 5.92 & 57.53 \\
\hline
\end{tabular}


replaced by equation (7). As discussed in Section 2.2, we regard equation (2) as preferable on empirical grounds, but it is of interest to see what effect our use of that specification has had on the results.

Table 7 indicates that with no bubble, the alternative Phillips curve does provide support for a strong exchange rate response, although the improvement in welfare comes entirely from lower interest rate variability (measured by $4 * \Delta R$ ); inflation and output gap variability actually rise in the $\phi_{q}>0$ case. When a bubble is present, again a large response to the real exchange rate is favored, and its effect continues to be mainly to reduce interest rate volatility. Thus, if one believes that the exchange rate is as important for price setting as it is in (7), then there may be a case for a nonzero value of $\phi_{q}$ in reaction functions such as (9). However, we believe that (7) gives an exaggerated impression of the importance of the exchange rate for inflation behavior, and that (2) is more reasonable. And, as Tables 3 and 5 above showed, this preferred specification does not support a response to the exchange rate separate from the response to expected inflation.

\section{Extensions}

In this section, we present two extensions. The first allows agents to view the bubble probabilistically. The second alters the structure of our model by dropping uncovered interest parity and forward-looking price setting.

\subsection{Allowing Agents to View the Bubble Probabilistically}

Our experiments in Section 4 did not allow agents—-within each simulation— to account for the probabilistic nature of the bubble's duration. One formulation that allows agents to attach probability to the bubble bursting next period (to the exchange rate returning to fundamentals next period) is:

$$
p \mathrm{E}_{t} q_{t+1}+(1-p) \mathrm{E}_{t} q_{t+1}{ }^{F U N}=q_{t}+R_{t}-\mathrm{E}_{t} \pi_{t+1}+\kappa_{t}+z_{t}
$$


$\mathrm{E}_{t} q_{t+1}^{F U N}=q_{t}^{F U N}+R_{t}-\mathrm{E}_{t} \pi_{t+1}+\kappa_{t}$.

Equation (14) replaces $\mathrm{E}_{q} q_{t+1}$ in (3) with a linear combination of itself and of the fundamental value, $\mathrm{E}_{\mathrm{t}} q_{t+1}{ }^{F U N}$, that - as equation (14) indicates-would prevail in the absence of any bubble. We set $p=0.6$ (so that agents have the correct probability that the bubble will burst next period). Equations (13)-(14) take us most of the way to a situation where agents take full account of the probabilistic nature of the bubble's termination date: they apply the correct probabilities ( 0.4 and 0.6$)$ to the bubble being present and absent next period. ${ }^{19}$

Because (13)-(14) collapse to the UIP condition (3) in the case of no bubble, the only results in Tables 2 and 3 that need to be re-calculated are those where the bubble is operative. The results of using eqs. (13)-(14) instead of (3) are given in Table 8. If agents view the bubble probabilistically, the bubble's effect is dampened-future expectations of the real exchange rate and (through the reaction function (9)) the nominal interest rate are restrained. Consequently, the loss function outcomes in Tables 2 and 3 tend to be less unfavorable than those in Tables 2 and 3. Nevertheless, the results of Section 4 carry through: there does not appear to be a welfare gain from responding specifically to asset prices.

\subsection{Dropping Forward-Looking Price-Setting in Goods and Foreign Exchange Markets}

This section presents results that investigate the implications of dropping the uncovered interest parity (UIP) and forward-looking price setting assumptions used in our model.

The uncovered interest parity condition—equation (3) in this paper-is a key element of most open-economy macroeconomic models, as an arbitrage condition that emerges from

\footnotetext{
${ }^{19}$ The only sense in which it does not is that having a probability over the bubble would affect not only the conditional expectation of $q_{t+1}$ but also the conditional expectation of $\pi_{t+1}$. To avoid keeping track of a whole sequence of "bubble-operative" and "no bubble" versions of endogenous variables, we opt for the simpler formulation given in (13)-(14).
} 
Table 8: Rule Performances When Agents Model the Bubble Probabilistically

\begin{tabular}{|c|c|c|c|c|c|}
\hline \multicolumn{6}{|c|}{ Bubble Operative, Rule Coefficients Not Optimized } \\
\hline & $\sigma(4 * \pi)$ & $\sigma(y)$ & $\sigma\left(4^{*} \Delta R\right)$ & $\sigma(q)$ & Loss \\
\hline$R_{t}=1.01 \mathrm{E} \pi_{t+1}$ & 12.25 & 1.93 & 2.77 & 5.27 & 157.62 \\
\hline$R_{t}=2.0 \mathrm{E} \pi_{t+1}$ & 4.01 & 1.75 & 4.22 & 3.60 & 28.05 \\
\hline$R_{t}=1.01 \mathrm{E}_{t} \pi_{t+1}+0.9 R_{t-1}$ & 3.27 & 2.13 & 2.37 & 4.84 & 18.01 \\
\hline$R_{t}=2.0 \mathrm{E} \pi_{t+1}+0.9 R_{t-1}$ & 2.96 & 2.17 & 3.92 & 7.50 & 21.19 \\
\hline$R_{t}=1.01 \mathrm{E}_{t} \pi_{t+1}+0.025 q_{t-1}$ & 12.89 & 1.83 & 2.71 & 4.85 & 173.46 \\
\hline$R_{t}=2.0 \mathrm{E} \pi_{t+1}+0.025 q_{t-1}$ & 4.07 & 1.75 & 4.29 & 4.39 & 28.85 \\
\hline$R_{t}=1.01 \mathrm{E} \pi_{t+1}+0.9 R_{t-1}+0.025 q_{t-1}$ & 3.31 & 2.04 & 2.50 & 6.89 & 18.26 \\
\hline$R_{t}=2.0 \mathrm{E} \pi_{t+1}+0.9 R_{t-1}+0.025 q_{t-1}$ & 3.00 & 2.13 & 4.10 & 8.51 & 21.92 \\
\hline$R_{t}=1.01 \mathrm{E} \pi_{t+1}+0.9 R_{t-1}+0.050 q_{t-1}$ & 8.93 & 5.44 & 20.61 & 85.94 & 321.66 \\
\hline \multicolumn{6}{|c|}{ Results with Bubble Operative, Rule Coefficients Optimized } \\
\hline $\begin{array}{l}\text { Horizon fixed at one quarter, } \phi_{\pi} \text { and } \\
\rho_{R} \text { optimized in }(9), \phi_{q}=0 \text { imposed: }\end{array}$ & & & & & \\
\hline$R_{t}=0.79 \mathrm{E}_{t} \pi_{t+1}+0.9 R_{t-1}$ & 3.37 & 2.11 & 1.96 & 5.97 & 17.69 \\
\hline $\begin{array}{l}\text { Horizon fixed at one quarter, } \phi_{\pi} \text { and } \\
\rho_{R} \text { optimized in }(9), \phi_{q}>0 \text { allowed: }\end{array}$ & & & & & \\
\hline$R_{t}=0.79 \mathrm{E}_{t} \pi_{t+1}+0.9 R_{t-1}+0.00 q_{t-1}$ & 3.37 & 2.11 & 1.96 & 5.97 & 17.69 \\
\hline $\begin{array}{l}\text { Horizon optimized, } \phi_{\pi} \text { and } \rho_{R} \\
\text { optimized in (9), } \phi_{q}=0 \text { imposed: }\end{array}$ & & & & & \\
\hline$R_{t}=1.11 \mathrm{E} \pi_{t+2}+0.89 R_{t-1}+0.00 q_{t-1}$ & 3.45 & 1.96 & 1.97 & 4.55 & 17.65 \\
\hline $\begin{array}{l}\text { Horizon optimized, } \phi_{\pi} \text { and } \rho_{R} \\
\text { optimized in (9), } \phi_{q}>0 \text { allowed: }\end{array}$ & & & & & \\
\hline$R_{t}=1.11 \mathrm{E}_{t} \pi_{t+2}+0.89 R_{t-1}$ & 3.45 & 1.96 & 1.97 & 4.55 & 17.65 \\
\hline $\begin{array}{l}\text { Adding arbitrary coefficients on } q_{t-1} \\
\text { to optimized rule: }\end{array}$ & & & & & \\
\hline$R_{t}=1.11 \mathrm{E}_{t} \pi_{t+2}+0.89 R_{t-1}+0.025 q_{t-1}$ & 3.84 & 1.84 & 1.99 & 5.99 & 20.12 \\
\hline$R_{t}=1.11 \mathrm{E} \pi_{t+2}+0.89 R_{t-1}+0.05 q_{t-1}$ & 4.27 & 2.00 & 4.31 & 16.56 & 31.52 \\
\hline
\end{tabular}


forward-looking behavior by foreign exchange market participants under free movement of perfectly substitutable foreign and domestic securities. McCallum (1994) notes that the UIP condition is a core equation in many policy institutions' macroeconomic models.

At the same time, however, unrestricted econometric estimates tend to reject the restrictions necessary to generate the UIP condition. Blundell-Wignall, Fahrer, and Heath (1993, p. 73) observe that "[n]o economic hypothesis has been rejected more decisively, over more time periods, and for more countries, than UIP," and Wadhwani (1999) extensively documents the poor fit of the equation on UK data. ${ }^{20}$ The response by many macro-modellers - including ourselves in Section 2 above-has typically been to model the empirical deviations from strict uncovered interest parity ${ }^{21}$ as though they are a structural shock process, interpretable as a time-varying risk premium. On the other hand, a growing amount of analysis is conducted with models that respond to the rejection of UIP by replacing it with an alternative exchange rate equation which, while continuing to posit a relationship between exchange rates and the interest rate differential, allows some deviation from the forward-looking arbitrage condition embodied in UIP. Ball (1999), for example, employs in a small analytical model a static relationship between the real exchange rate and the real interest rate, which we write as:

$q_{t}=-b\left(R_{t}-\mathrm{E}_{t} \pi_{t+1}\right)+e_{t}$,

with $b>0$. This equation is a version of (3) provided we drop $\mathrm{E}_{t} q_{t+1}$, set $b=1.0$, and interpret the shock $e_{t}$ as $-\left(\kappa_{t}+z_{t}\right)$. Wadhwani (1999) and Beechey et al (2000) provide empirical models of the exchange rate for the UK and Australia, respectively, which can be regarded as alternatives to UIP, and share some similarities with (15). Given the importance for practical policy making of contemplating alternative specifications to UIP, we report in this section results based on simulations of our model with equation (15), specialized to the case $b=1.0$, replacing equation (3). Since specification (15) is

\footnotetext{
${ }^{20}$ McCallum (1994) provides a rationalization for the empirical rejection of UIP in terms of policymakers' reaction functions. Wadhwani, however, presents experiments that suggest that this factor may not fully account for the rejection of UIP by UK exchange rate data.

${ }^{21}$ Strict UIP is equation (3) without the $\kappa_{t}$ and $z_{t}$ terms.
} 
Table 9: One-period-ahead inflation forecast based rules

(coefficients not optimized)

No forward looking price setters and

UIP dropped, replaced by equation (15)

\begin{tabular}{|l|c|c|c|c|c|}
\hline \multicolumn{5}{|c|}{ Results with No Bubble } & Loss \\
\hline & $\sigma(4 * \pi)$ & $\sigma(y)$ & $\sigma(4 * \Delta R)$ & $\sigma(q)$ & \\
\hline$R_{t}=1.01 \mathrm{E} \pi_{t+1}$ & 12.43 & 1.57 & 2.09 & 1.40 & 159.28 \\
\hline$R_{t}=2.0 \mathrm{E} \pi_{t+1}$ & 4.00 & 1.86 & 3.69 & 1.59 & 26.26 \\
\hline$R_{t}=1.01 \mathrm{E} \pi_{t+1}+0.9 R_{t-1}$ & 3.15 & 2.51 & 2.40 & 2.21 & 19.26 \\
\hline$R_{t}=2.0 \mathrm{E} \pi_{t+1}+0.9 R_{t-1}$ & 2.85 & 2.69 & 4.14 & 2.79 & 23.91 \\
\hline$R_{t}=1.01 \mathrm{E} \pi_{t+1}+0.025 q_{t-1}$ & 12.46 & 1.56 & 2.09 & 1.38 & 159.95 \\
\hline$R_{t}=2.0 \mathrm{E} \pi_{t+1}+0.025 q_{t-1}$ & 4.61 & 1.86 & 3.70 & 1.57 & 26.42 \\
\hline$R_{t}=1.01 \mathrm{E} \pi_{t+1}+0.9 R_{t-1}+0.025 q_{t-1}$ & 3.14 & 2.46 & 2.46 & 2.13 & 18.95 \\
\hline$R_{t}=2.0 \mathrm{E} \pi_{t+1}+0.9 R_{t-1}+0.025 q_{t-1}$ & 2.84 & 2.64 & 4.13 & 2.72 & 23.59 \\
\hline$R_{t}=1.01 \mathrm{E} \pi_{t+1}+0.9 R_{t-1}+0.050 q_{t-1}$ & 3.14 & 2.42 & 2.47 & 2.07 & 18.75 \\
\hline \multicolumn{7}{|c|}{ Results with Bubble Operative } & & \\
\hline$R_{t}=1.01 \mathrm{E} \pi_{t+1}$ & 12.41 & 1.56 & 2.09 & 1.38 & 158.39 \\
\hline$R_{t}=2.0 \mathrm{E} \pi_{t+1}$ & 3.97 & 1.88 & 3.68 & 1.56 & 26.06 \\
\hline$R_{t}=1.01 \mathrm{E} \pi_{t+1}+0.9 R_{t-1}$ & 3.15 & 2.50 & 2.46 & 2.16 & 19.21 \\
\hline$R_{t}=2.0 \mathrm{E} \pi_{t+1}+0.9 R_{t-1}$ & 2.84 & 2.68 & 4.13 & 2.75 & 23.84 \\
\hline$R_{t}=1.01 \mathrm{E} \pi_{t+1}+0.025 q_{t-1}$ & 12.13 & 1.56 & 2.10 & 1.36 & 150.65 \\
\hline$R_{t}=2.0 \mathrm{E} \pi_{t+1}+0.025 q_{t-1}$ & 4.03 & 1.88 & 3.71 & 1.54 & 26.63 \\
\hline$R_{t}=1.01 \mathrm{E} \pi_{t+1}+0.9 R_{t-1}+0.025 q_{t-1}$ & 3.14 & 2.45 & 2.46 & 2.11 & 18.88 \\
\hline$R_{t}=2.0 \mathrm{E} \pi_{t+1}+0.9 R_{t-1}+0.025 q_{t-1}$ & 2.85 & 2.65 & 4.15 & 2.69 & 23.73 \\
\hline$R_{t}=1.01 \mathrm{E} \pi_{t+1}+0.9 R_{t-1}+0.050 q_{t-1}$ & 3.12 & 2.40 & 2.46 & 2.03 & 18.54 \\
\hline & & & \\
\hline
\end{tabular}

Note: For the no-bubble case, standard deviations and loss function values are obtained using analytical formulae for the vector autoregressive representation of the solution of the model. For the operative-bubble cases, these moments and losses reported are the averages across stochastic simulations, as described in Section 3. The standard deviation of the real exchange rate is reported as a memo item only; there is no exchange rate term in the loss function (10). 
only one of many alternatives to UIP that could be contemplated, we will not attempt to obtain optimized versions of rule (9) subject to this specification. Instead we simply report, for illustration, the performance under this alternative specification of the nonoptimized versions of rule (9) that we used in Table 2 (including those rules examined by Bernanke and Gertler, 1999). ${ }^{22}$

In these experiments, we also drop another key element of forward-looking behavior by setting $\alpha=1.0$ in the price setting equation (2). Thus, the experiments contemplated are for an economy in which there is considerably less forward-looking behavior in the pricing of goods and assets.

The results in Table 9 are different from those for the baseline model in two respects: $(a)$ There are, generally, improvements in welfare from including a response to the exchange rate. (b) Responding to the exchange rate in bubble conditions does not result in greatly increased losses; rather, the response to the exchange rate improves welfare. This result confirms, as suggested in our discussion in Section 4, that the expectational dynamics associated with UIP were responsible for the sharply higher losses when policy responded to an exchange rate bubble. Intuitively, responding to the exchange rate bubble is now more desirable because (as substitution of (15) into (1) indicates) the bubble now has the character of a "large" IS shock.

One response to Table 9 is that UIP is a standard element of open-economy macro models and a fundamental arbitrage condition, and that alternative specifications should be ruled out a priori. An alternative response is that the size of empirical violations of UIP makes it necessary to consider alternatives such as (15). Table 9 suggests that, if one takes the second position, there are some gains to responding to the exchange rate over and above expected inflation.

\footnotetext{
${ }^{22}$ For comparability with Section 4, we revert to the assumption that agents do not view the bubble probabilistically.
} 


\section{Conclusions}

In this paper we have investigated the appropriate form of simple interest rate feedback rules when the economy is hit by several shocks including, for a certain amount of time, an explosive "bubble" shock which perturbs the uncovered interest parity condition governing the exchange rate.

In Section 4, using the model we used in Batini and Nelson (2000), we found that the optimal response of monetary policy to asset prices was fully captured by their effect on expected inflation. In the absence of a bubble, responding to the exchange rate separately did reduce exchange rate variability but did not, in most cases, improve overall welfare because inflation variability increased. With a bubble present, reacting to the exchange rate did not even necessarily reduce exchange rate volatility, and led to poorer welfare outcomes.

In Section 5.2, we adopted a more backward-looking version of the model, to capture the concern that uncovered interest parity may not be an empirically valid description of exchange rate behavior. The alternative to UIP that we contemplated generated results that were more supportive of incorporating a response to the exchange rate. Therefore, a crucial issue in determining whether it is appropriate to respond to exchange rates is whether one views the UIP condition as an essential part of the structure of a macroeconomic model or whether one prefers alternative specifications, such as those of Ball (1999) or Wadhwani (1999).

There are several issues raised by the analysis that are possible future extensions. First, by expressing our model in terms of deviations from the steady state, we have taken it for granted that the monetary authority knows the steady-state value of the real exchange rate, $q^{s s}$. In the more realistic case, $q^{s s}$ is unknown or may vary in response to structural changes in the domestic and international economies. A policy that responds to deviations of the exchange rate from its steady-state value must then rest on an estimate of $q^{s s}$ that is subject to measurement error. Our conjecture is that introducing this 
measurement error would reduce the attractiveness of rules that feed back on the exchange rate. Certainly, imprecise knowledge about $q^{s s}$ appears to have played a role in motivating the central banks of Canada and New Zealand to reduce the weight placed by policy on Monetary Conditions Indices, which, when used as operating targets, include the deviation of the real exchange rate from its steady-state level as an integral component.

Another extension is to generalise the results to alternative specifications of the effects of asset prices on aggregate demand. For example, one possibility is that private agents may react to the bubble and non-bubble components of an asset price with different elasticities. Development of macroeconomic models to enrich the links between asset prices and the economy - and investigation of the implied appropriate form of monetary policy rules-are important areas for future research. 


\section{References}

Allen, Franklin, and Douglas Gale (2000). "Asset Price Bubbles and Monetary Policy." Working Paper, University of Pennsylvania.

Amato, Jeffery D., and Thomas Laubach (2000). "Forecast-Based Monetary Policy." Working Paper, Federal Reserve Board.

Ball, Laurence (1999). “Policy Rules for Open Economies.” In J.B. Taylor (ed), Monetary Policy Rules. Chicago: University of Chicago Press. 127-144.

Batini, Nicoletta, and Andrew G. Haldane (1999). "Forward-Looking Rules for Monetary Policy.” In: J.B. Taylor (ed.), Monetary Policy Rules. Chicago: University of Chicago Press. 157-192.

Batini, Nicoletta, and Kenny Turnbull (2000). "Monetary Conditions Indices for the UK: A Survey.” External MPC Unit Discussion Paper No. 1, Bank of England.

Beechey, Meredith, Nargis Bharucha, Adam Cagliarini, David Gruen, and Christopher Thompson (2000). "A Small Model of the Australian Macroeconomy." Reserve Bank of Australia Research Discussion Paper 2000-05.

Bergin, Paul R., and Robert C. Feenstra (1999). "Pricing to Market, Staggered Contracts, and Real Exchange Rate Persistence.” NBER Working Paper No. 7026.

Bernanke, Ben S., and Mark Gertler (1999). "Monetary Policy and Asset Price Volatility," in: New Challenges for Monetary Policy: A Symposium Sponsored by the Federal Reserve Bank of Kansas City. Federal Reserve Bank of Kansas City. 77-128. Also published in Federal Reserve Bank of Kansas City Economic Review, Fourth Quarter 1999, 17-51. 
Blanchard, Olivier, and Mark W. Watson (1982). "Bubbles, Rational Expectations, and Financial Markets." In P. Wachtel (ed.), The Crisis in the Economic and Financial Structure. Lexington. 79-100.

Blundell-Wignall, Adrian, Jerome Fahrer, and Alexandra Heath (1993). "Major Influences on the Australian Dollar Exchange Rate". In Adrian Blundell-Wignall (ed.), The Exchange Rate, International Trade and the Balance of Payments. Sydney: Reserve Bank of Australia. 30-78.

Borensztein, Eduardo R., (1987). “Alternative Hypotheses About the Excess Return on Dollar Assets, 1980-84," International Monetary Fund Staff Papers 34, $29-59$.

Cecchetti, Stephen G., Hans Genberg, John Lipski, and Sushil Wadhwani (2000). "Asset Prices and Central Bank Policy." CEPR Working Paper.

Charemza, Wojciech W. (1996). "Detecting Stochastic Bubbles on an East European Foreign Exchange Market: An Estimation/Simulation Approach," Structural Change and Economic Dynamics 7, 35-53.

Clarida, Richard, Jordi Gali, and Mark Gertler (1999). "The Science of Monetary Policy: A New Keynesian Perspective,” Journal of Economic Literature 37, 1661-1707.

Cogley, Timothy, (1999). "Should the Fed Take Deliberate Steps to Deflate Asset Price Bubbles?," Federal Reserve Bank of San Francisco Economic Review 1, 42-52.

Erceg, Christopher J., Dale W. Henderson, and Andrew T. Levin (1999). “Optimal Monetary Policy with Staggered Wage and Price Contracts.” International Finance Discussion Paper 1999-640, Federal Reserve Board.

Evans, George W. (1986). “A Test for Speculative Bubbles in the Sterling-Dollar Exchange Rate: 1981-84," American Economic Review 76, 621-636. 
Fuhrer, Jeffrey C (1997). "The (Un)importance of Forward-Looking Behavior in Price Specifications," Journal of Money, Credit, and Banking 29, 338-350.

Fuhrer, Jeffrey C., and George R. Moore (1995). “Inflation Persistence,” Quarterly Journal of Economics 109, 127-159.

Goodhart, Charles A.E., and Boris Hofmann (2000). "Asset Prices and the Conduct of Monetary Policy." Working paper, London School of Economics.

Grossman, Sanford J., and Robert J. Shiller (1981). "The Determinants of the Variability of Stock Market Prices”, American Economic Review 71, 222-227.

Hamilton, James D. (1994). Time Series Analysis. Princeton: Princeton University Press.

Kent, Christopher, and Philip Lowe (1997). "Asset-Price Bubbles and Monetary Policy." Reserve Bank of Australia Research Discussion Paper No. 9709.

Levin, Andrew T., Volker W. Wieland, and John C. Williams (2000). “The Performance of Forecast-Based Monetary Policy Rules under Model Uncertainty.” Working paper, Federal Reserve Board.

McCallum, Bennett T. (1983). “On Non-Uniqueness in Rational Expectations Models: An Attempt at Perspective," Journal of Monetary Economics 11, 139-168.

McCallum, Bennett T. (1994). "A Reconsideration of the Uncovered Interest Parity Relationship," Journal of Monetary Economics 33, 105-132.

McCallum, Bennett T. (1999b). "Role of the Minimal State Variable Criterion in Rational Expectations Models,” in: P. Isard, A. Razin, and A.K. Rose (eds.), International Finance and Financial Crises: Essays in Honor of Robert P. Flood, Jr. 
Norwell, MA: Kluwer Academic Publishers. Also published in International Tax and Public Finance 6, 621-639.

McCallum, Bennett T. and Edward Nelson (1999a), "Performance of Operational Policy Rules in an Estimated Semi-Classical Structural Model.” In: J.B. Taylor (ed.), Monetary Policy Rules. Chicago: University of Chicago Press. 15-45.

McCallum, Bennett T. and Edward Nelson (1999b). "Nominal Income Targeting in an Open-Economy Optimizing Model," Journal of Monetary Economics 43, 553-578.

Monacelli, Tommaso (1999a). "Into the Mussa Puzzle: Monetary Policy Regimes and the Real Exchange Rate in a Small Open Economy." Working paper, New York University.

Monacelli, Tommaso (1999b). “Open-Economy Policy Rules Under Imperfect PassThrough.” Working paper, New York University.

Mussa, Michael L. (1986). "Nominal Exchange Rate Regimes and the Behavior of Real Exchange Rates: Evidence and Implications," Carnegie-Rochester Conference Series on Public Policy 25, 117-214.

Nelson, Edward (2000a). "Direct Effects of Base Money on Aggregate Demand: Theory and Evidence." Bank of England Working Paper No. 122.

Nelson, Edward (2000b). "UK Monetary Policy 1972-1997: A Guide Using Taylor Rules.” Bank of England Working Paper No. 120.

Okina, Kunio (1984). "Rational Expectations, Bubbles and Foreign Exchange Market," Bank of Japan Monetary and Economic Studies, 2, 81-118. 
Roberts, John M. (1997). “Is Inflation Sticky?,” Journal of Monetary Economics 39, 173-196.

Rotemberg, Julio J., and Michael Woodford (1999). "Interest Rate Rules in an Estimated Sticky Price Model.” In: J.B. Taylor (ed.), Monetary Policy Rules. Chicago: University of Chicago Press. 57-119.

Rudebusch, Glenn D. (2000). “Assessing Nominal Income Rules for Monetary Policy with Model and Data Uncertainty." Working paper, Federal Reserve Bank of San Francisco.

Rudebusch, Glenn D., and Lars E.O. Svensson (1999). "Policy Rules for Inflation Targeting." In J.B. Taylor (ed.), Monetary Policy Rules. Chicago: University of Chicago Press. 203-246.

Stock, James H., and Mark W. Watson (2000). "Forecasting Output and Inflation: The Role of Asset Prices." Working paper, Harvard University.

Vickers, John (1999). "Monetary Policy and Asset Prices," Bank of England Quarterly Bulletin 39, 428-435.

Wadhwani, Sushil B. (1999). “Currency Puzzles.” Working paper, Bank of England.

Woodford, Michael (1999). "Inflation Stabilization and Welfare." In Interest and Prices. Manuscript, Princeton University.

Wu, Yangru (1995). “Are There Rational Bubbles in Foreign Exchange Markets?

Evidence from an Alternative Test," Journal of International Money and Finance 14, $27-$ 46. 